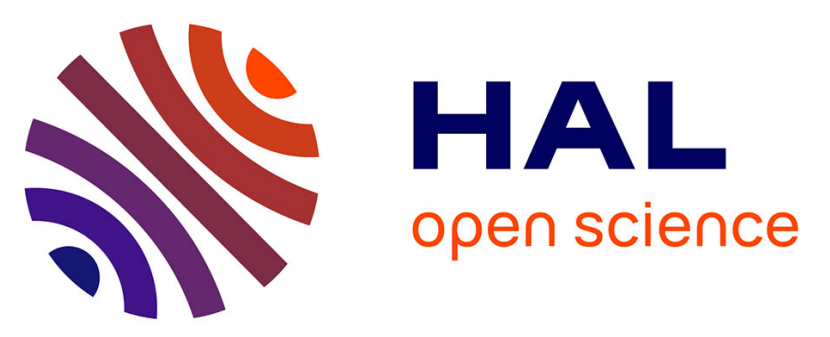

\title{
The primary stages of polyoxomolybdate catalyzed cyclohexanone oxidation by hydrogen peroxide as investigated by in situ NMR. Substrate activation and evolution of the working catalyst
}

Dahbia Amitouche, Mohamed Haouas, Tassadit Mazari, Sihem Mouanni, Romain Canioni, Chérifa Rabia, Emmanuel Cadot, Catherine Marchal-Roch

\section{To cite this version:}

Dahbia Amitouche, Mohamed Haouas, Tassadit Mazari, Sihem Mouanni, Romain Canioni, et al.. The primary stages of polyoxomolybdate catalyzed cyclohexanone oxidation by hydrogen peroxide as investigated by in situ NMR. Substrate activation and evolution of the working catalyst. Applied Catalysis A : General, 2018, 561, pp.104-116. 10.1016/j.apcata.2018.05.017 . hal-02335610

\author{
HAL Id: hal-02335610 \\ https://hal.science/hal-02335610
}

Submitted on 17 Jan 2021

HAL is a multi-disciplinary open access archive for the deposit and dissemination of scientific research documents, whether they are published or not. The documents may come from teaching and research institutions in France or abroad, or from public or private research centers.
L'archive ouverte pluridisciplinaire HAL, est destinée au dépôt et à la diffusion de documents scientifiques de niveau recherche, publiés ou non, émanant des établissements d'enseignement et de recherche français ou étrangers, des laboratoires publics ou privés. 


\title{
The primary stages of polyoxomolybdate catalyzed cyclohexanone oxidation by hydrogen peroxide as investigated by in situ NMR. Substrate activation and evolution of the working catalyst.
}

Dahbia Amitouche, ${ }^{\mathrm{a}, \mathrm{b}, \mathrm{c}}$ Mohamed Haouas, ${ }^{\mathrm{a}, *}$ Tassadit Mazari, ${ }^{\mathrm{b}, \mathrm{c}}$ Sihem Mouanni, ${ }^{\mathrm{b}, \mathrm{c}}$ Romain Canioni, ${ }^{a}$ Chérifa Rabia, ${ }^{\text {b,c }}$ Emmanuel Cadot, ${ }^{a}$ Catherine Marchal-Roch ${ }^{\mathrm{a}}$

a Institut Lavoisier de Versailles, CNRS UMR 8180, Univ. Versailles Saint Quentin, Université Paris-Saclay, 45 av. des Etats-Unis, 78035 Versailles cedex (France).

${ }^{\mathrm{b}}$ Laboratoire de Chimie du Gaz Naturel, Faculté de Chimie, Université des Sciences et de la Technologie Houari Boumediene (USTHB), BP 32, El-Alia, 16111 Bab-Ezzouar, Alger, Algeria.

${ }^{\mathrm{c}}$ Département de Chimie, Faculté des Sciences, Université Mouloud Mammeri (UMMTO), 15000 Tizi Ouzou, Algeria

\begin{abstract}
The catalytic process of cyclohexanone oxidation by hydrogen peroxide was investigated using in situ NMR spectroscopy in real working conditions. The behavior of the Keggin heteropolyacid $\mathrm{H}_{3} \mathrm{PMo}_{12} \mathrm{O}_{40}$, used as a model catalyst, was explored before and after adding the oxidant agent. This study revealed the evolution pathways to different reduced states of $\mathrm{H}_{3} \mathrm{PMo}_{12} \mathrm{O}_{40}$ and its reversible transformation into peroxomolybdate complexes. These latter were identified as the active species for the adipic acid formation, while the acid function of the catalyst was found important for the substrate activation via ketonic-enolic tautomerism. The oxidative mechanism of the cyclohexanone was described through three successive steps to produce adipic acid.
\end{abstract}

Keywords:

Nuclear magnetic resonance

Operando spectroscopy

Multinuclear NMR

Phosphomolybdate polyanions 


\section{Introduction}

The worldwide demand for clean chemical processes has expanded greatly in recent decades [1]. Intense efforts have therefore been devoted to the development of catalytic systems employing benign reagents with respect to the environment [2]. The utilization of green oxidants, such as oxygen (or air) or hydrogen peroxide $\left(\mathrm{H}_{2} \mathrm{O}_{2}\right)$, together with environmentally friendly solvents, such as water, is of particular interest in catalytic oxidation processes [3-9]. $\mathrm{H}_{2} \mathrm{O}_{2}$ is particularly attractive reagent not only due to its high contents of active oxygen species, but also because its reduction leads only to water as by-product [10].

Adipic acid is of a great interest in the manufacture of various commercially valuable products such as nylon-6,6 and polyamide [11-13]. The current industrial procedure of its production is based on two-step process [14], where cyclohexane is first oxidized in presence of air to a mixture of cyclohexanol and cyclohexanone (first step), which is further oxidized to adipic acid by nitric acid (second step). During this process, the used nitric acid causes the $\mathrm{N}_{2} \mathrm{O}$ emission, which is obviously an undesired byproduct [15, 16]. Others efficient ecologically friendly catalysts are therefore needed to replace nitric acid.

Polyoxometalates (POMs) consisting of a large family of anionic metal-oxygen nanoscopic clusters [17-20] have especially received much attention in the area of the oxidation catalysis because of their strong oxidative effeciency beside their strong Brønsted and Lewis acidities $[21,22]$. In particular, molybdenum based POMs have been shown to be effective catalysts for green oxidations using $\mathrm{H}_{2} \mathrm{O}_{2}$ or $\mathrm{O}_{2}$ [23-27]. The remarkable catalytic activities of POMs could be related to the multifunctional character of the active sites at their surface. For instance, their ability to activate simultaneously the substrate and oxidant is well recognized by stabilizing reaction intermediates, and facilitating oxygen or multi-electron transfer [26-31]. Although catalytic performance of POMs is widely studied and in some cases well established, there is still a lack of rational and systematic use of knowledge. The need for kinetic and mechanistic studies is obvious to shed light on the intimate mechanisms of oxidative transformation.

Previous studies revealed different mechanisms of organic substrates oxidation catalyzed by POMs and reaction pathways were found to be dependent on reaction conditions and catalytic systems [32-34]. In this respect, diverse experimental approaches for the investigation of the catalytic behavior of material under working conditions were developed, in particular, spectroscopic methods [35-37]. Among these techniques, NMR spectroscopy is 
considered to be one of the most informative, since it allows following the fate of both reactant and catalyst during the time course of the reaction [38-40]. Furthermore, it offers the possibility to obtain quantitative results on the transformations of the substrates and thus permits to study reaction kinetics in situ [41].

In this study, the early stages of cyclohexanone oxidative conversion, in presence of the Keggin type phosphomolybdate anion $\mathrm{PMo}_{12} \mathrm{O}_{40}{ }^{3-}$, are investigated in situ by means of multinuclear $\left({ }^{95} \mathrm{Mo},{ }^{31} \mathrm{P},{ }^{17} \mathrm{O}\right.$, and $\left.{ }^{1} \mathrm{H}\right) \mathrm{NMR}$ spectroscopy. The evolution of the chemical state of $\mathrm{PMo}_{12} \mathrm{O}_{40}{ }^{3-}$ during the catalytic cycle is revealed as well as the activated form of the substrate allowing to suggest a general mechanism of the catalytic process. The initial experimental conditions (substrate and catalyst concentrations, solvent, amount of $\mathrm{H}_{2} \mathrm{O}_{2}$, etc.) have found to affect greatly the stability of the catalyst and its evolution.

\section{Experimental section}

\subsection{Chemicals and materials}

1,4-Dioxane (99.5\%, Sds), $\mathrm{N}_{2} \mathrm{H}_{4} \cdot \mathrm{H}_{2} \mathrm{O}$ (98\%, Alfa Aesar), $\mathrm{H}_{3} \mathrm{PO}_{4}$ (85wt\% in water, Merck), $\mathrm{Na}_{2} \mathrm{MoO}_{4} \cdot 2 \mathrm{H}_{2} \mathrm{O}$ (99.5\% Sigma-Aldrich), $\mathrm{H}_{2} \mathrm{O}_{2}$ (30wt\% in water, Sigma-Aldrich), $\mathrm{D}_{2} \mathrm{O}(99.90 \% \mathrm{D}$, euriso-top), cyclohexanone (99.0\%, Prolabo), and tetrabutylammonium bromide (99.0\%, Acros Organics), were used as obtained from commercial suppliers. Hydrogen peroxide concentration was verified by potassium permanganate titration.

\subsection{Physical methods}

\subsubsection{Fourier Transform Infrared (FT-IR) and UV-Vis spectroscopies}

FT-IR spectra were recorded on a 6700 FT-IR Nicolet spectrophotometer, using diamond ATR technique. UV-Vis spectra were measured on a Lambda 19 Perkin Elmer spectrophotometer in $0.1 \mathrm{~cm}$ quartz cell. To monitor formation of the reduced species as a function of time, a solution of the initial oxidized $\mathrm{H}_{3}\left[\mathrm{PMo}_{12} \mathrm{O}_{40}\right]$ in 50/50 (v/v) water/dioxane mixture is prepared and then one equivalent of hydrazine is added. The electronic spectra were recorded every $2 \mathrm{~h}$ over $66 \mathrm{~h}$ of total measurement time. 


\subsubsection{Nuclear magnetic resonance (NMR) spectroscopy}

Spectra were recorded on a Bruker Avance $500 \mathrm{MHz}$ spectrometers using standard $10 \mathrm{~mm}$ NMR tubes and fixing sample volume to $3 \mathrm{~mL}$. Typically, ${ }^{1} \mathrm{H}$ NMR spectra were obtained accumulating 8 scans and using $1 \mathrm{~s}$ acquisition time, $15 \mathrm{~s}$ relaxation delay, and $24 \mu \mathrm{s}$ pulse length $\left(\pi / 2\right.$ flip angle). ${ }^{31} \mathrm{P}$ NMR spectra were recorded with 32 numbers of scans, $1 \mathrm{~s}$ acquisition time, $51 \mathrm{~s}$ relaxation delay, and $15 \mu$ s pulse length ( $\pi / 2$ flip angle). The ${ }^{17} \mathrm{O}$ NMR spectra were recorded with an accumulation of ca. 2000000 scans, $0.02 \mathrm{~s}$ acquisition time, 0.1 $\mathrm{s}$ relaxation delay, and $10 \mu$ s pulse length ( $\pi / 2$ flip angle). ${ }^{95} \mathrm{Mo}$ NMR spectra were run using ca. 16000 scans, $0.2 \mathrm{~s}$ acquisition time, $0.1 \mathrm{~s}$ relaxation delay, and $3 \mu$ s pulse length ( $\pi / 12$ flip angle). Chemical shifts were referenced to external standards $(\delta=0 \mathrm{ppm})$ that are Tetramethylsilane for ${ }^{1} \mathrm{H}, 85 \mathrm{wt} \% \mathrm{H}_{3} \mathrm{PO}_{4}$ for ${ }^{31} \mathrm{P}, \mathrm{H}_{2} \mathrm{O}$ for ${ }^{17} \mathrm{O}$, and $2 \mathrm{M} \mathrm{Na}_{2} \mathrm{MoO}_{4}$ aqueous solution for ${ }^{95} \mathrm{Mo}$. The variable temperature experiments were conducted using a Eurotherm temperature unit within the range $30-70{ }^{\circ} \mathrm{C}$, and the actual temperature in the tube was calibrated using ethylene glycol protocol reported in the literature [42]. Various in situ experimental conditions were investigated and some typical experiments were as follows: i) $m$ $\mathrm{PMo}_{12}+3 \mathrm{~mL} \mathrm{D} \mathrm{D}_{2} \mathrm{O} / \mathrm{H}_{2} \mathrm{O}_{2}$; ii) $m \mathrm{PMo}_{12}+3 \mathrm{~mL}$ cyclohexanone $/ \mathrm{H}_{2} \mathrm{O}_{2}$; iii) $m \mathrm{PMo}_{12}+0.5 \mathrm{~mL}$ cyclohexanone $+2.5 \mathrm{~mL} \mathrm{D} \mathrm{D}_{2} \mathrm{O} / \mathrm{H}_{2} \mathrm{O}$; where $m=30$ or $300 \mathrm{mg}$. These experiments where conducted for two different temperatures, namely $27{ }^{\circ} \mathrm{C}$ or $55^{\circ} \mathrm{C}$. $\mathrm{D}_{2} \mathrm{O}$ was introduced only when it is possible in aqueous phase, while in neat cyclohexanone system no lock was used.

\subsection{Syntheses of the Keggin phosphomolybdate and its reduced derivatives}

The compound $\mathrm{H}_{3}\left[\mathrm{PMo}_{12} \mathrm{O}_{40}\right] \cdot 13 \mathrm{H}_{2} \mathrm{O}$ was prepared as described by Courtin [43]. FTIR/ $/ \mathrm{cm}^{-1}$ (Diamond ATR, ATR correction applied): $1064\left(\mathrm{P}-\mathrm{O}_{\mathrm{a}}\right), 961\left(\mathrm{Mo}=\mathrm{O}_{\mathrm{t}}\right), 869\left(\mathrm{Mo}-\mathrm{O}_{\mathrm{b}}-\right.$ $\mathrm{Mo}), 786$ (Mo- $\left.\mathrm{O}_{\mathrm{c}}-\mathrm{Mo}\right)$. The control of kinetic parameters (temperature and time) is essential for the selective isolation of the reduced derivatives. These parameters are determined according to preliminary kinetics studies (see section 3.2.1). The optimal conditions for formation and isolation of the corresponding tetrabutylammonium (TBA) salts are as follow.

\subsubsection{TBA ${ }_{4} H\left[\alpha-P M o_{12} O_{40}\right]$, abbreviated $T B A_{4} H\{\alpha-I I\}$}


In a flask, $5 \mathrm{~mL}$ of a $50 / 50(\mathrm{v} / \mathrm{v})$ water/dioxane solution of $\mathrm{H}_{3}\left[\mathrm{PMo}_{12} \mathrm{O}_{40}\right]\left(\mathrm{C}=6.010^{-2}\right.$ $\mathrm{M})$, is mixed with $600 \mu \mathrm{L}$ of a hydrazine solution $(\mathrm{C}=0.53 \mathrm{M})$. The molar ratio $\mathrm{H}_{3}\left[\mathrm{PMo}_{12} \mathrm{O}_{40}\right]: \mathrm{N}_{2} \mathrm{H}_{4}$ was fixed to $1: 1$. The mixture was stirred for $24 \mathrm{~h}$ at room temperature and the product was then isolated as a TBA salt precipitate after adding $587 \mathrm{mg}$ of TBABr (1.8 mmol). FT-IR/cm ${ }^{-1}$ (Diamond ATR, ATR correction applied): $1059\left(\mathrm{P}-\mathrm{O}_{\mathrm{a}}\right), 954\left(\mathrm{Mo}=\mathrm{O}_{\mathrm{t}}\right)$, $857\left(\mathrm{Mo}-\mathrm{O}_{\mathrm{b}}-\mathrm{Mo}\right), 794\left(\mathrm{Mo}-\mathrm{O}_{\mathrm{c}}-\mathrm{Mo}\right)$.

\subsection{2 $\mathrm{TBA}_{3} \mathrm{H}_{4}\left[\alpha-\mathrm{PMo}_{12} \mathrm{O}_{40}\right]$ abbreviated $\mathrm{TBA}_{3} \mathrm{H}_{4}\{\alpha-I V\}$}

In a flask, $5 \mathrm{~mL}$ of a 50/50 (v/v) water/dioxane solution of $\mathrm{H}_{3}\left[\mathrm{PMo}_{12} \mathrm{O}_{40}\right]\left(\mathrm{C}=6.010^{-2}\right.$ $\mathrm{M})$, is mixed with $600 \mu \mathrm{L}$ of a hydrazine solution $(\mathrm{C}=0.53 \mathrm{M})$. The molar ratio $\mathrm{H}_{3}\left[\mathrm{PMo}_{12} \mathrm{O}_{40}\right]: \mathrm{N}_{2} \mathrm{H}_{4}$ was fixed to $1: 1$. The mixture was stirred for $45 \mathrm{~h}$ at room temperature and the product was then isolated as a TBA salt precipitate after adding $440 \mathrm{mg}$ of $\mathrm{TBABr}$ (1.35 mmol). FT-IR/ $\mathrm{cm}^{-1}$ (Diamond ATR, ATR correction applied): $1059\left(\mathrm{P}-\mathrm{O}_{\mathrm{a}}\right), 951$ $\left(\mathrm{Mo}=\mathrm{O}_{\mathrm{t}}\right), 876\left(\mathrm{Mo}-\mathrm{O}_{\mathrm{b}}-\mathrm{Mo}\right), 799-768\left(\mathrm{Mo}-\mathrm{O}_{\mathrm{c}}-\mathrm{Mo}\right)$.

\subsection{3 $\mathrm{TBA}_{3} \mathrm{H}_{4}\left[\beta-\mathrm{PMo}_{12} \mathrm{O}_{40}\right]$ abbreviated $\mathrm{TBA}_{3} \mathrm{H}_{4}\{\beta-I V\}$}

In a flask, $5 \mathrm{~mL}$ of a $50 / 50(\mathrm{v} / \mathrm{v})$ water/dioxane solution of $\mathrm{H}_{3}\left[\mathrm{PMo}_{12} \mathrm{O}_{40}\right]\left(\mathrm{C}=3.010^{-2}\right.$ $\mathrm{M})$, is mixed with $109 \mu \mathrm{L}$ of a hydrazine solution $(\mathrm{C}=2.06 \mathrm{M})$. The molar ratio $\mathrm{H}_{3}\left[\mathrm{PMo}_{12} \mathrm{O}_{40}\right]: \mathrm{N}_{2} \mathrm{H}_{4}$ was fixed to $1: 1.5$. The mixture was heated at $70{ }^{\circ} \mathrm{C}$ under stirring for $3 \mathrm{~h}$ and the product was then isolated as a TBA salt precipitate after adding $220 \mathrm{mg}$ of TBABr (0.68 mmol). FT-IR/cm ${ }^{-1}$ (Diamond ATR, ATR correction applied): $966-952\left(\mathrm{Mo}=\mathrm{O}_{\mathrm{t}}\right)$.

In the solid state, the derivatives $\mathrm{TBA}_{4} \mathrm{H}\{\alpha-\mathrm{II}\}$ and $\mathrm{TBA}_{3} \mathrm{H}_{4}\{\alpha-\mathrm{IV}\}$ are not stable and undergo slow reoxydation, as shown by their color change to green after few weeks. The $\{\beta-$ IV\} compound appears however much more stable over time.

\subsection{Catalytic reaction}

The adipic acid synthesis was carried out according to procedure of previous studies [44, 45]. The oxidation of cyclohexanone in homogeneous phase was performed under reflux at 90 ${ }^{\circ} \mathrm{C}$. A POM color change from yellow to blue green (characteristic color for intervalence transfert between $\mathrm{Mo}^{\mathrm{V}}$ and $\mathrm{Mo}^{\mathrm{VI}}$ ) is observed. Then, $0.5 \mathrm{~mL}$ of hydrogen peroxide $(30 \%)$ was added to restore the $\mathrm{Mo}^{\mathrm{VI}}$ oxidation state of the catalyst, characterized by yellow color. This 
sequence is repeated after each color change until there is no more change of color. At that moment, the reaction end is reached and the POM catalyst is no longer reduced. The resultant homogeneous mixture was cooled at $4{ }^{\circ} \mathrm{C}$ overnight to isolate adipic acid by cold crystallization and its identification was made by means of FT-IR and NMR spectroscopy and also its characteristic melting point at $152^{\circ} \mathrm{C}$.

\section{Results and discussion}

\subsection{Catalytic tests}

Some catalytic tests were conducted in order to search the reaction conditions of the liquid-phase cyclohexanone oxidation to adipic acid by hydrogen peroxide. It is emphasized that the adipic acid synthesis requires both presence of substrate and catalyst, and hydrogen peroxide must be added gradually after each reduction of the catalyst by the substrate. In this work, the effects of catalyst/substrate molar ratio, solvent presence and reaction time on adipic acid yield were examined.

Table 1 summarizes the adipic acid yield obtained for the different reaction conditions studied. The highest yield recorded was obtained after $20 \mathrm{~h}$ reaction at $90{ }^{\circ} \mathrm{C}$ using $30 \mathrm{mg}$ of catalyst in $3.16 \mathrm{~mL}$ (30 mmol) cyclohexanone. Increase of the catalyst loading or decrease of the substrate amount reduced the product yield. However, an optimum catalyst/substrate ratio of $30 \mathrm{mg}$ for $30 \mathrm{mmol}$ was found for the highest adipic acid yield. Finally, presence of organic solvent inhibited the catalytic reaction.

Table 1: Adipic acid yield (\%) as a function of reaction conditions. ${ }^{\text {a }}$

\begin{tabular}{ccccc}
\hline $\begin{array}{c}\text { Reaction time } \\
\text { (h) }\end{array}$ & $\begin{array}{c}\text { Catalyst weight } \\
(\mathbf{m g})\end{array}$ & $\begin{array}{c}\text { Substrate amount } \\
(\mathbf{m m o l})\end{array}$ & $\begin{array}{c}\text { Solvent } \\
\text { reaction time effect }\end{array}$ & $\begin{array}{c}\text { Adipic acid yield } \\
(\mathbf{\%}) \mathbf{b}\end{array}$ \\
\hline 8 & & 30 & none & 23 \\
14 & 30 & 30 & none & 31 \\
20 & 30 & 30 & none & 43 \\
26 & 30 & 30 & none & 36 \\
20 & 30 & catalyst weight effect & & \\
20 & 30 & 30 & none & 43 \\
20 & 60 & 30 & none & 36 \\
20 & 90 & 30 & none & 41 \\
& 120 & 30 & none & 39 \\
\hline
\end{tabular}




\begin{tabular}{ccccc}
\hline 20 & 30 & 15 & none & 21 \\
20 & 30 & 30 & none & 43 \\
20 & 30 & 45 & none & 35 \\
20 & 30 & 60 & none & 33 \\
20 & 30 & 75 & none & 22 \\
20 & 30 & & & \\
20 & 30 & 30 & none & 43 \\
20 & 30 & 30 & $\mathrm{CH}_{3} \mathrm{COOH}$ & 17 \\
20 & 30 & 30 & $\mathrm{CH}_{3} \mathrm{CN}$ & 32 \\
20 & 30 & 30 & $\mathrm{CH}_{3} \mathrm{OH}$ & 0 \\
\hline
\end{tabular}

a) Fixed reaction conditions: reaction temperature $=90{ }^{\circ} \mathrm{C}$, agitation rate $=1000 \mathrm{rpm}$, amount of successive addition of $\mathrm{H}_{2} \mathrm{O}_{2}(30 \mathrm{wt} \%)=0.5 \mathrm{ml}$. ${ }^{\text {b) }}$ based on weight of isolated product. ${ }^{\mathrm{c})}$ volume of solvent $=3.16 \mathrm{~mL}$ (equal to volume of substrate for $30 \mathrm{mmol})$.

In summary, these preliminary catalytic tests allowed identifying the optimum reaction conditions with $\mathrm{H}_{3} \mathrm{PMo}_{12}$ catalyst. The best results were obtained using $\mathrm{H}_{3} \mathrm{PMo}_{12} /$ cyclohexanone molar ratio of $510^{-4}$ corresponding to a catalyst mass of $30 \mathrm{mg}$ and substrate amount of $30 \mathrm{mmol}$, after 20 hours of reaction under agitation in solvent free medium. The next sections will be devoted to determine the evolution of the catalyst and to study the course of the reaction at molecular level.

\subsection{The chemical states of the catalyst}

In order to identify the different states of the catalyst, a preliminary study of the reduction of the $\left[\mathrm{PMo}_{12} \mathrm{O}_{40}\right]^{3-}$ anion was carried out in solution combining NMR and UV-Vis spectroscopies. Furthermore, the solution behavior of the POM catalyst in presence of $\mathrm{H}_{2} \mathrm{O}_{2}$ was also studied by means of multinuclear NMR spectroscopy. These studies aim to identify and characterize the different forms of the POM for the catalytic oxidation of cyclohexanone by hydrogen peroxide.

\subsubsection{Reduced species of POMs}

The most stable isomer of the anion $\left[\mathrm{PMo}_{12} \mathrm{O}_{40}\right]^{3-}$, in its oxidized state, is the $\alpha$ form (denoted $\{\alpha-0\})$ of $T_{\mathrm{d}}$ symmetry. A preliminary electrochemical study showed that it was possible to successively form a 2 -electron reduced derivative (denoted $\{\alpha-\mathrm{II}\}$ ), followed by a 4-electron reduced derivative (denoted $\{\alpha-I V\}$ ). This latter then underwent a structural evolution toward a more stable isomer (denoted $\{\beta-\mathrm{IV}\}$ ) of $C_{3 \mathrm{v}}$ symmetry. This isomerization 
results from the formal rotation of $60^{\circ}$ of a trimeric group $\left\{\mathrm{Mo}_{3} \mathrm{O}_{13}\right\}$, probably associated with a minimization of the coulombic repulsions within the polyanionic structure. Experimentally, during the electrolysis, we observed a decomposition of the reduced POM above 4 electrons in $\mathrm{pH}$ conditions of the study.

In 2000, Yamase et al. have described the photoreduction process of an aqueous solution of $\mathrm{H}_{3}\left[\alpha-\mathrm{PMo}_{12} \mathrm{O}_{40}\right]$ at $\mathrm{pH}=2$ by methanol [46]. They were able to isolate and record the structures of the derivatives $\{\alpha-\mathrm{II}\}$ and $\{\beta-\mathrm{IV}\}$ by single crystal X-ray diffraction and to follow the evolution of the reaction by ${ }^{31} \mathrm{P}$ NMR. More recently, Maksimovskaya studied the electron-transfer reactions in molybdophosphate heteropoly blues using ${ }^{31} \mathrm{P} \mathrm{NMR}$, revealing one-, two-, and four-electron reduced $\left[\mathrm{PMo}_{12} \mathrm{O}_{40}\right]^{\mathrm{n}-}$ species in aqueous solutions [47].

Based on the ${ }^{31} \mathrm{P}$ NMR chemical shifts of the compounds $\{\alpha-\mathrm{II}\}$ and $\{\beta-\mathrm{IV}\}$, their syntheses were optimized in order to isolate these reduced derivatives. In this work, the reduced derivatives syntheses were carried out by solubilizing the $\mathrm{H}_{3} \mathrm{PMo}_{12} \mathrm{O}_{40}$ acid in a water/dioxane medium in the presence of hydrazine, used as a reducing agent capable of supplying four electrons according to the following equation: $\mathrm{N}_{2} \mathrm{H}_{4} \rightarrow \mathrm{N}_{2}+4 \mathrm{H}^{+}+4 \mathrm{e}^{-}$. The reduced derivatives were isolated from the reaction medium by precipitation with tetrabutylammonium cation. The saturated salt solutions in water/dioxane before precipitation were analyzed by ${ }^{31} \mathrm{P}$ NMR. These spectra are presented in Fig. 1.

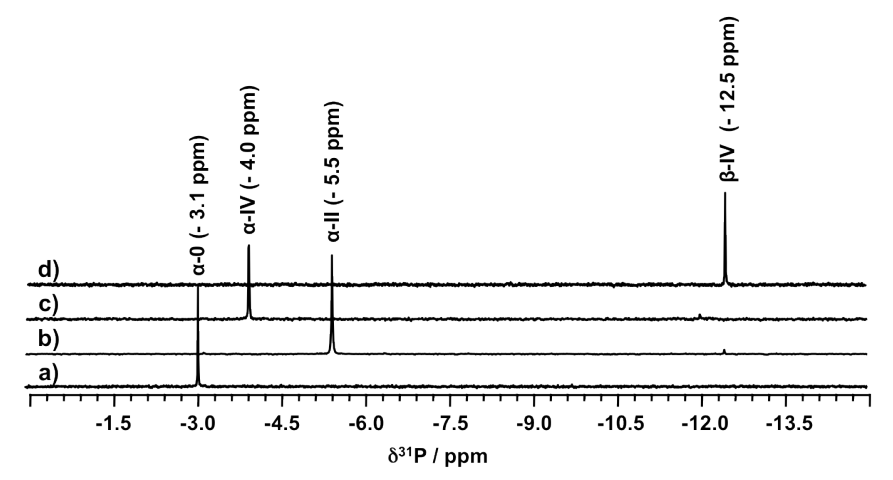

Fig. 1: Room temperature $\left(27^{\circ} \mathrm{C}\right){ }^{31} \mathrm{P}$ NMR spectra in $50: 50 \mathrm{D}_{2} \mathrm{O}$ :dioxane solutions of a) the oxidized Keggin anion $\left[\mathrm{PMo}_{12} \mathrm{O}_{40}\right]^{3-}\{\alpha-0\}$, and reduced derivatives b) $\left.\left[\mathrm{PMo}_{12} \mathrm{O}_{40}\right]^{5-}\{\alpha-\mathrm{II}\}, \mathrm{c}\right)\left[\mathrm{PMo}_{12} \mathrm{O}_{40}\right]^{7-}\{\alpha-\mathrm{IV}\}$, and d) $\left[\mathrm{PMo}_{12} \mathrm{O}_{40}\right]^{7-}\{\beta-\mathrm{IV}\}$ : a) $60 \mathrm{mM}$ of $\mathrm{H}_{3}\left[\mathrm{PMo}_{12} \mathrm{O}_{40}\right]$; b) after addition of 1 eq. $\mathrm{N}_{2} \mathrm{H}_{2}$ to the POM solution in a) and $24 \mathrm{~h}$ room temperature stirring; c) after addition of 1 eq. $\mathrm{N}_{2} \mathrm{H}_{2}$ to the POM solution in a) and $45 \mathrm{~h}$ room temperature stirring; d) after addition of 1.5 eq. $\mathrm{N}_{2} \mathrm{H}_{2}$ to the $\mathrm{POM}$ solution in a) and $3 \mathrm{~h}$ stirring at $70{ }^{\circ} \mathrm{C}$. 
The oxidized ion, $\left[\mathrm{PMo}_{12} \mathrm{O}_{40}\right]^{3-}\{\alpha-0\}$, has a characteristic resonance at $-3.1 \mathrm{ppm}$. Its reduction to 2 electrons causes a significant change in chemical shift at $-5.5 \mathrm{ppm}$, characteristic of a shielding of the ${ }^{31} \mathrm{P}$ nucleus. The introduction of two other additional electrons $(\alpha-\mathrm{IV})$ results in phosphorus deshielding $(\delta=-4.0 \mathrm{ppm})$, while the isomerization of the $\{\alpha-I V\}$ ion to $\{\beta-I V\}$ has an opposite effect resulting in the appearance of a peak at -12.5 ppm. In conclusion, the reduction of the ion $\left[\mathrm{PMo}_{12} \mathrm{O}_{40}\right]^{3-}$ causes a shielding of the ${ }^{31} \mathrm{P}$ nucleus and an increase in the charge of the polyanion that generates weak acidities responsible of the POM protonation. Thus, the variation in the chemical shift of the phosphorus core could be due to two antagonistic effects: i) a shielding associated with the introduction of electrons into the POM framework, and ii) a deshielding resulting from the protonation and therefore the change in the acidity strength. Moreover, the isomerization that results in a significant variation of the chemical shift towards negative values, causes besides a structural modification associated with a lowering of the symmetry, a modification of the $4 \mathrm{~d}$ electrons distribution and therefore acidity modification.

UV-Vis study was carried out to further characterize the different phosphomolybdate species formed in solution in presence of reducing agent. The curve of $t=0 \mathrm{~h}$ in Fig. 2 corresponds to the electronic spectrum of the starting acid $\mathrm{H}_{3}\left[\mathrm{PMo}_{12} \mathrm{O}_{40}\right]\{\alpha-0\}$ before addition of hydrazine. It does not absorb in the visible. The bands at 200 and $312 \mathrm{~nm}$ are attributed to $\mathrm{O} \rightarrow \mathrm{Mo}^{\mathrm{VI}}$ charge transfer. However, these bands are wide enough and intense to allow a weak absorption at the visible limit, thus giving a yellow color. On the other hand, the broad absorptions observed in the visible and near-infrared domains, between 400 and 1200 $\mathrm{nm}$ during the reduction of the $\left[\mathrm{PMo}_{12} \mathrm{O}_{40}\right]^{-3}$ ion, are due to $\mathrm{Mo}^{\mathrm{VI}} \rightarrow \mathrm{Mo}^{\mathrm{V}}$ intervalence electronic transitions responsible for the dark blue color of the solution. This is therefore a direct evidence of the reduction of POM. The addition of hydrazine to the starting yellow solution of the POM instantly causes a blue-green color characteristic of the reduction of the polyanion. The reduction results in the rapid growth of the bands at 520 and $785 \mathrm{~nm}$. The maximum observed at $785 \mathrm{~nm}$ is typical of the reduced two-electron derivative $\{\alpha-\mathrm{II}\}$. The formation of the four-electron derivative $\{\alpha-\mathrm{IV}\}$ takes longer time and results in a decrease in the absorbance of the $785 \mathrm{~nm}$ band in favor of two new bands at 710 and $900 \mathrm{~nm}$. The formation of the isomerized four-electron derivative $\{\beta-\mathrm{IV}\}$ at room temperature is too slow and was not observed in this experiment. Its electronic spectrum could nevertheless be 
recorded from the synthesis solution described in experimental part 2.2.3 after verification by ${ }^{31} \mathrm{P}$ NMR.

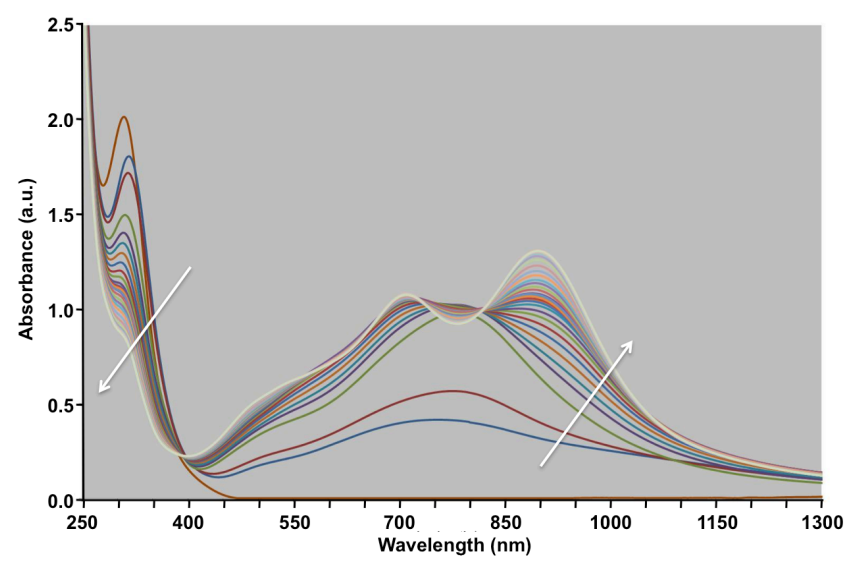

Fig. 2: UV-Vis kinetics monitoring the transformation of $\left[\mathrm{PMo}_{12} \mathrm{O}_{40}\right]^{3-}\{\alpha-0\}$ into their reduced derivatives, $\left[\mathrm{PMo}_{12} \mathrm{O}_{40}\right]^{5-}\{\alpha-\mathrm{II}\}$ and $\left[\mathrm{PMo}_{12} \mathrm{O}_{40}\right]^{7-}\{\alpha-\mathrm{IV}\}$ at room temperature under the effect of hydrazine. The measurements start immediately after addition of 1 eq. $\mathrm{N}_{2} \mathrm{H}_{2}$ to $0.6 \mathrm{mM}$ of $\mathrm{H}_{3}\left[\mathrm{PMo}_{12} \mathrm{O}_{40}\right]$ in $50: 50 \mathrm{H}_{2} \mathrm{O}$ :dioxane solution over a period of $66 \mathrm{~h}$ at $27^{\circ} \mathrm{C}$. The arrows indicate the direction of evolution of spectra with time.

UV-Vis of the oxidized parent $\{\alpha-0\}$ and the isolated reduced derivatives, as twoelectrons $\{\alpha-\mathrm{II}\}$, four electrons $\{\alpha-\mathrm{IV}\}$, and isomer four electrons $\{\beta-\mathrm{IV}\}$, are also recorded and the spectra are superimposed in Fig. 3. The isomerization to $\{\beta-\mathrm{IV}\}$ results in the decrease of the absorption located at $710 \mathrm{~nm}$, the growth of the maximum observed at 900 $\mathrm{nm}$, as well as the lowering of the wavelengths of these characteristic bands by approximately $35 \mathrm{~nm}$ relative to that observed with its $\alpha$-isomer counterpart $\{\alpha$-IV $\}$.

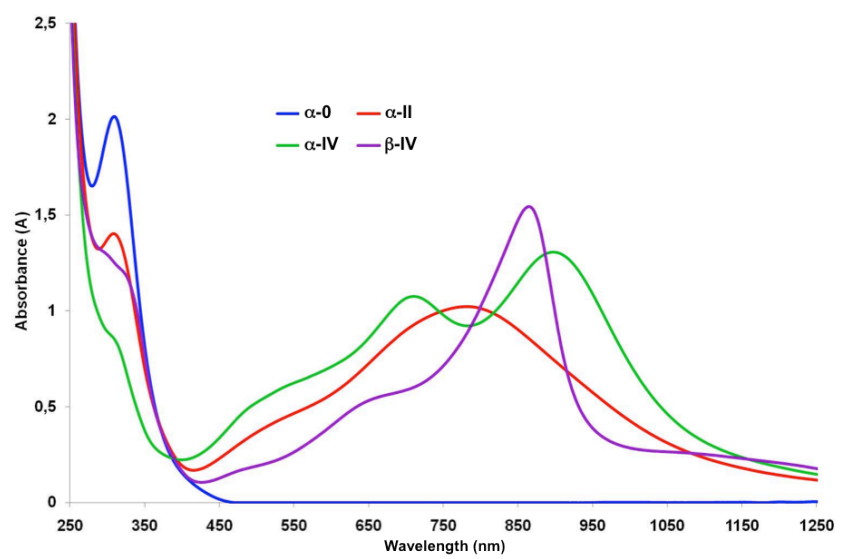

Fig. 3: Room temperature $\left(27^{\circ} \mathrm{C}\right) \mathrm{UV}$-Vis spectra in 50:50 $\mathrm{H}_{2} \mathrm{O}$ :dioxane solutions of the parent $\left[\mathrm{PMo}_{12} \mathrm{O}_{40}\right]^{3-}$ $\{\alpha-0\}$ and the isolated reduced derivatives, $\left[\mathrm{PMo}_{12} \mathrm{O}_{40}\right]^{5-}\{\alpha-\mathrm{II}\},\left[\mathrm{PMo}_{12} \mathrm{O}_{40}\right]^{7-}\{\alpha-\mathrm{IV}\}$, and $\left[\mathrm{PMo}_{12} \mathrm{O}_{40}\right]^{7-}\{\beta-\mathrm{IV}\}$ : 
a) $0.6 \mathrm{mM}$ of $\mathrm{H}_{3}\left[\mathrm{PMo}_{12} \mathrm{O}_{40}\right]$; b) after addition of 1 eq. $\mathrm{N}_{2} \mathrm{H}_{2}$ to the POM solution in a) and $24 \mathrm{~h}$ room temperature stirring ; c) after addition of 1 eq. $\mathrm{N}_{2} \mathrm{H}_{2}$ to the POM solution in a) and $45 \mathrm{~h}$ room temperature stirring; d) after addition of 1.5 eq. $\mathrm{N}_{2} \mathrm{H}_{2}$ to the POM solution in a) and $3 \mathrm{~h}$ stirring at $70{ }^{\circ} \mathrm{C}$.

The evolution of the POM species in the presence of hydrazine, as a function of time at $70{ }^{\circ} \mathrm{C}$, was then monitored by means of ${ }^{31} \mathrm{P}$ NMR spectroscopy. Just before ${ }^{31} \mathrm{P}$ NMR analysis, 1.5 equivalents of hydrazine was added to $60 \mathrm{mM} \mathrm{H} \mathrm{H}_{3}\left[\mathrm{PMo}_{12} \mathrm{O}_{40}\right]$ in $\mathrm{D}_{2} \mathrm{O}$ /dioxane (50/50) solution. Spectra were recorded every $10 \mathrm{~min}$ during $5 \mathrm{~h}$, total reaction time. The integration of the different peaks, now identified, gives an overview of the evolution of these species over time and allows determination of their distribution as a function of time (Fig. 4).

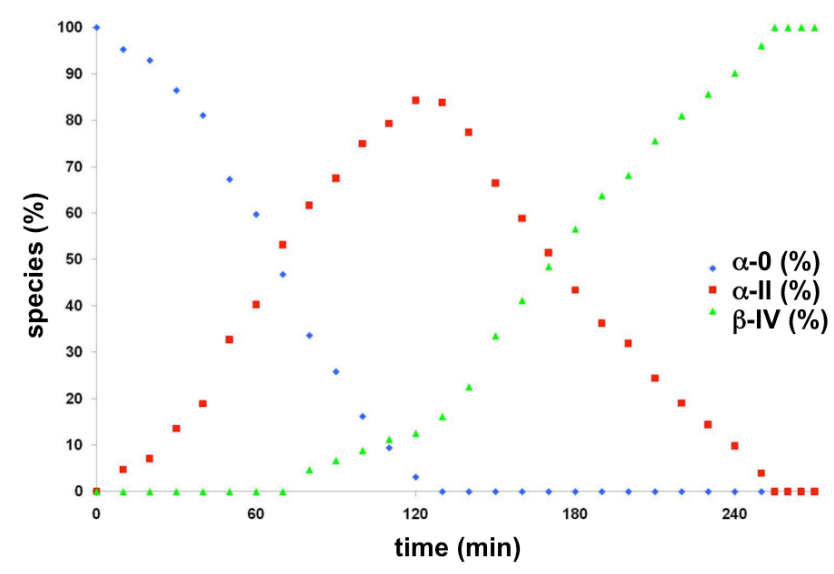

Fig. 4: Evolution of the oxidized Keggin anion $\left[\mathrm{PMo}_{12} \mathrm{O}_{40}\right]^{3-}\{\alpha-0\}$ toward reduced derivatives $\left[\mathrm{PMo}_{12} \mathrm{O}_{40}\right]^{5-}\{\alpha-$ $\mathrm{II}\}$ and $\left[\mathrm{PMo}_{12} \mathrm{O}_{40}\right]^{7-}\{\beta-\mathrm{IV}\}$ at $70{ }^{\circ} \mathrm{C}$ as a function of time as measured by ${ }^{31} \mathrm{P}$ NMR. The measurements start immediately after addition of 1.5 eq. $\mathrm{N}_{2} \mathrm{H}_{2}$ to $60 \mathrm{mM}$ of $\mathrm{H}_{3}\left[\mathrm{PMo}_{12} \mathrm{O}_{40}\right]$ in $50: 50 \mathrm{D}_{2} \mathrm{O}$ :dioxane solution.

The obtained results show disappearance of the signal at $-3.1 \mathrm{ppm}$, characteristic of the oxidized species $\{\alpha-0\}$ during the first two hours and the appearance of a signal at $-5.45 \mathrm{ppm}$ assigned to the two electrons reduced species $\{\alpha-\mathrm{II}\}$ followed by that of the isomerized fourelectron derivative $\{\beta-\mathrm{IV}\}(\delta=-12.5 \mathrm{ppm})$. This latter appears clearly as the final product after $4.5 \mathrm{~h}$ of reaction, whereas the $\{\alpha-\mathrm{II}\}$ species is an intermediate with a maximum amount at ca. $2 \mathrm{~h}$. In this study, the non-isomerized four-electron derivative $\{\alpha-\mathrm{IV}\}(\delta=-4.0 \mathrm{ppm})$ was not observed. Under the conditions of the experiment $\left(\mathrm{T}=70{ }^{\circ} \mathrm{C}\right)$, the isomerization process is too fast and proceeds quasi simultaneously as soon as the compound $\{\alpha-\mathrm{IV}\}$ is formed. Reduction of $\mathrm{H}_{3}\left[\mathrm{PMo}_{12} \mathrm{O}_{40}\right]$ by hydrazine is a relatively slow process. Heating significantly accelerates the reaction leading to the most stable 4-electron derivative that is 
$\{\beta-I V\}$ anion. The latter no longer accepts electrons and when left in the presence of hydrazine, it decomposes as indicated by the appearance of a resonance peak due to phosphate ions.

\subsubsection{Peroxo species}

In the presence of hydrogen peroxide, POMs usually decompose into peroxo-based metalate (tungstate or molybdate) complexes [21, 23, 29, 32, 48-50]. In the case of phosphotungstate-peroxo complexes, the three main species identified by ${ }^{31} \mathrm{P}$ NMR using the scalar coupling ${ }^{2} J\left({ }^{31} \mathrm{P}_{-}{ }^{183} \mathrm{~W}\right)$ were $\left\{\mathrm{PO}_{4}\left[\mathrm{WO}\left(\mathrm{O}_{2}\right)_{2}\right]_{4}\right\}^{3-},\left\{\mathrm{PW}_{3} \mathrm{O}_{\mathrm{m}}\right\}^{\mathrm{n}-}$, and $\left\{\mathrm{PO}_{4}\left[\mathrm{WO}\left(\mathrm{O}_{2}\right)_{2}\right]_{2}\right\}^{2-}$, denoted $\mathrm{PW}_{4}, \mathrm{PW}_{3}$, and $\mathrm{PW}_{2}$ respectively $[48,49,51,52]$. Such species are known to play a key role in many oxidation reactions of organic substrates [53, 54]. With molybdenum-based POM catalysts, similar peroxomolybdate complexes were also suggested as intermediate active species [24].

In order to investigate the hydrogen peroxide action on the catalyst, $\mathrm{H}_{2} \mathrm{O}_{2}$ was progressively added to an aqueous solution of $\mathrm{H}_{3}\left[\mathrm{PMo}_{12} \mathrm{O}_{40}\right](58 \mathrm{mM})$. After each $\mathrm{H}_{2} \mathrm{O}_{2}$ addition, the solution was analyzed by ${ }^{31} \mathrm{P}$ NMR. The series of ${ }^{31} \mathrm{P}$ NMR spectra is presented in Fig. 5. The spectrum of the initial POM exhibits the characteristic signal of the Keggin phosphomolybdate at $-2.7 \mathrm{ppm}$. Upon addition of two equivalents of $\mathrm{H}_{2} \mathrm{O}_{2}$, two new resonance peaks appeared at -0.5 and $0.6 \mathrm{ppm}$ assigned to lacunary POMs $\left[\mathrm{PMo}_{11} \mathrm{O}_{39}\right]^{7-}$ and $\left[\mathrm{PMo}_{9} \mathrm{O}_{34}\right]^{9-}$, respectively [47]. Further addition of $\mathrm{H}_{2} \mathrm{O}_{2}$ (26 equivalents) led to the disappearance of all the previous signals and the appearance of three main broad resonances at $3.9,3.0$, and $1.8 \mathrm{ppm}$ that could be attributed to peroxomolybdate complexes, respectively, $\left\{\mathrm{PO}_{4}\left[\mathrm{MoO}\left(\mathrm{O}_{2}\right)_{2}\right]_{4}\right\}^{3-}\left(\mathrm{PMo}_{4}\right),\left\{\mathrm{PMo}_{3} \mathrm{O}_{\mathrm{m}}\right\}^{\mathrm{n}-}\left(\mathrm{PMo}_{3}\right)$, and $\left\{\mathrm{PO}_{4}\left[\mathrm{MoO}\left(\mathrm{O}_{2}\right)_{2}\right]_{2}\right\}^{2-}\left(\mathrm{PMo}_{2}\right)$, similar to $\mathrm{PW}_{4}, \mathrm{PW}_{3}$, and $\mathrm{PW}_{2}$ respectively. These latter showed peaks at 3.5, 2, and $0.4 \mathrm{ppm}$ in acetonitrile solutions [51]. Such results are fully consistent with progressive decomposition of the Keggin POM in presence of hydrogen peroxide and formation of novel peroxo complexes as discussed in the literature $[24,53,55]$. Nonetheless, peroxo tungstate complexes also showed ability to transform into Keggin derivative during oxidation of cyclopentene with aqueous $\mathrm{H}_{2} \mathrm{O}_{2}$ [56]. This would indicate reversible structural rearrangement of the catalyst during the catalytic processes. 


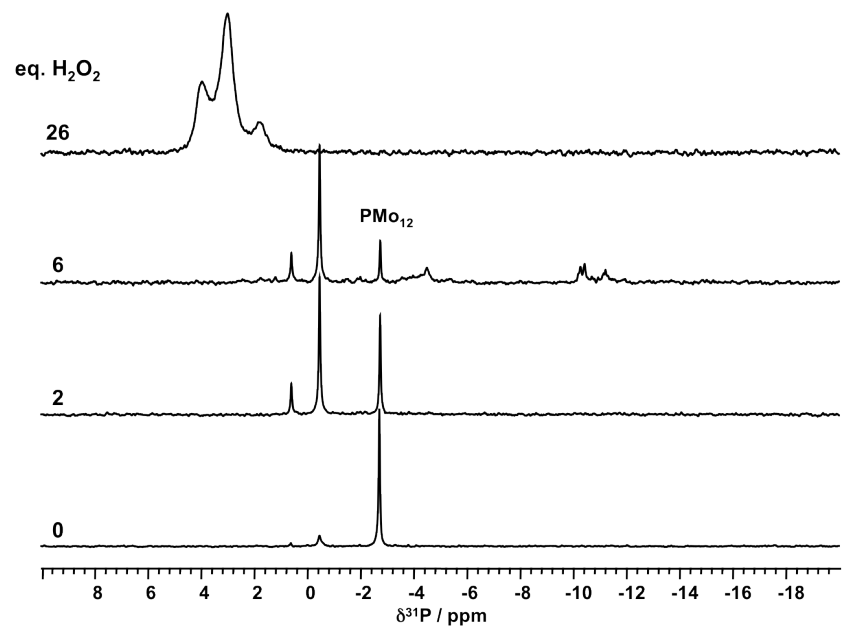

Fig. 5: ${ }^{31} \mathrm{P}$ NMR spectra of the Keggin anion $\left[\mathrm{PMo}_{12} \mathrm{O}_{40}\right]^{3-}$ in $\mathrm{H}_{2} \mathrm{O} / \mathrm{D}_{2} \mathrm{O}(58 \mathrm{mM})$ in the presence of $0,2,6$, and 26 equivalents of $\mathrm{H}_{2} \mathrm{O}_{2}$.

To further characterize the species present in the aqueous solution of $\left[\mathrm{PMo}_{12} \mathrm{O}_{40}\right]^{3-}$ in presence of hydrogen peroxide, ${ }^{95} \mathrm{Mo}$ NMR spectra were recorded for the same solutions used in ${ }^{31} \mathrm{P}$ NMR and the related results are shown in Fig. 6. The ${ }^{95} \mathrm{Mo}$ NMR spectrum of $\left[\mathrm{PMo}_{12} \mathrm{O}_{40}\right]^{3-}$ exhibits a characteristic broad signal at $21 \mathrm{ppm}$ [57]. After addition of few equivalences of $\mathrm{H}_{2} \mathrm{O}_{2}$, a shoulder at -14 ppm and a new resonance peak at -191 ppm appeared. The former could be assigned to lacunary Keggin $\left[\mathrm{PMo}_{11} \mathrm{O}_{39}\right]^{7-}$, and the second one to the peroxomolybdate complex $\mathrm{MoO}\left(\mathrm{O}_{2}\right)_{2}\left(\mathrm{H}_{2} \mathrm{O}\right)_{2}$, according to Talsi et al. [58]. In the presence of large excess of $\mathrm{H}_{2} \mathrm{O}_{2}$ (26 equivalents), all ${ }^{95} \mathrm{Mo}$ resonances were completely transformed into peroxomolybdate species with a main signal at $-191 \mathrm{ppm}$ and another one less intense at -242 ppm. These two signals should correspond to quite similar environments around the Mo center. The signal at $-242 \mathrm{ppm}$ is therefore tentatively assigned to $\mathrm{PMo}_{n}$ peroxo complexes ( $n$ $=3,4)$ as observed in ${ }^{31} \mathrm{P}$ NMR. It should be mentioned that such peroxo complexes would adopt a heptavalent configuration where the coordination sphere is completed by solvent molecules [36, 58, 59]. From the ${ }^{31} \mathrm{P}$ and ${ }^{95} \mathrm{Mo}$ NMR data, it appears clearly that the main molybdenum based peroxo species produced are $\mathrm{MoO}\left(\mathrm{O}_{2}\right)_{2}\left(\mathrm{H}_{2} \mathrm{O}\right)_{2}, \mathrm{PMo}_{4}, \mathrm{PMo}_{3}$, and $\mathrm{PMo}_{2}$. 


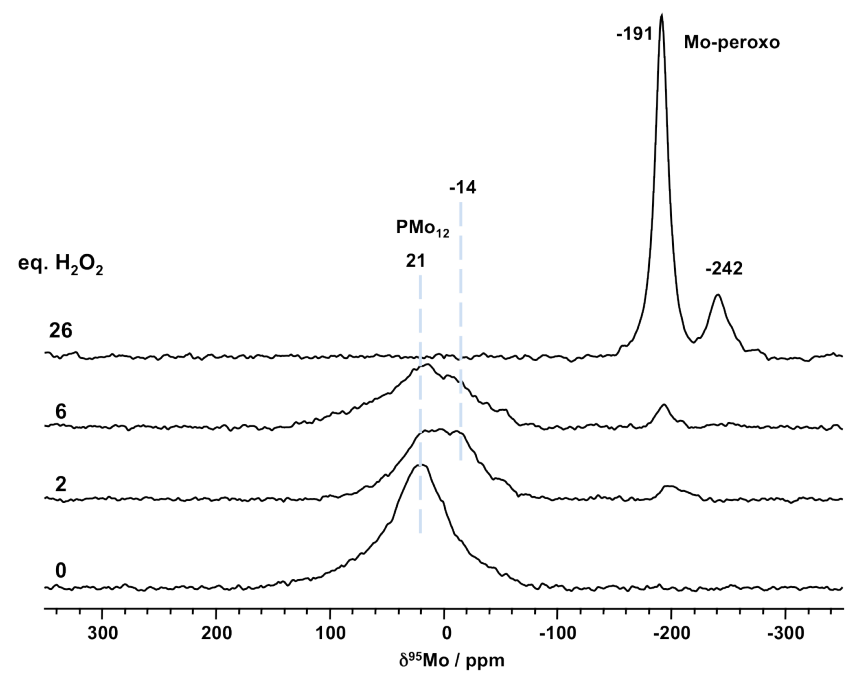

Fig. 6: ${ }^{95} \mathrm{Mo} N M R$ spectra of the Keggin anion $\left[\mathrm{PMo}_{12} \mathrm{O}_{40}\right]^{3-}$ in $\mathrm{H}_{2} \mathrm{O} / \mathrm{D}_{2} \mathrm{O}(58 \mathrm{mM})$, before and after adding 2, 6 , and 26 equivalents of $\mathrm{H}_{2} \mathrm{O}_{2}$.

Fig. 7 shows the ${ }^{17} \mathrm{O}$ NMR spectra of the phosphomolybdate species before and after addition of 6 and 26 equivalents of hydrogen peroxide. The spectrum of the starting compound exhibits the four expected resonances typical of the Keggin structure at 70, 551, 571, and 946 ppm assigned to $\left(\mathrm{P}-\mathrm{O}_{\mathrm{a}}\right),\left(\mathrm{Mo}-\mathrm{O}_{\mathrm{b}}-\mathrm{Mo}\right),\left(\mathrm{Mo}-\mathrm{O}_{\mathrm{c}}-\mathrm{Mo}\right)$, and $\left(\mathrm{Mo}=\mathrm{O}_{\mathrm{t}}\right)$ oxygen types, respectively [60]. These signals disappear upon addition of large excess of hydrogen peroxide and novel resonance peaks are observed, corresponding to the peroxo species formed. The signal at $872 \mathrm{ppm}$ and the very broad resonance at ca. $440 \mathrm{ppm}$, assigned to oxo $\mathrm{Mo}=\mathrm{O}$ and peroxo groups respectively, are characteristic of the peroxo molybdenum complex $\mathrm{MoO}\left(\mathrm{O}_{2}\right)_{2}\left(\mathrm{H}_{2} \mathrm{O}\right)_{2}$ in agreement with ${ }^{95} \mathrm{Mo}$ NMR results [58]. The intermediate spectrum after addition of 6 eq. $\mathrm{H}_{2} \mathrm{O}_{2}$ showed loosely defined signals of the starting Keggin anion and peroxo species present as minor products while signatures of prominent species, the lowsymmetrical lacunary Keggin $\left[\mathrm{PMo}_{11} \mathrm{O}_{39}\right]^{7-}$, according to ${ }^{31} \mathrm{P}$ and ${ }^{95} \mathrm{Mo} \mathrm{NMR}$, could not be observed at ${ }^{17} \mathrm{O}$ natural abundance level due to the dispersion of $\mathrm{O}$ sites. The signal at 181 ppm is assigned to $\mathrm{H}_{2} \mathrm{O}_{2}$, visible when this alter is used in large excess. 


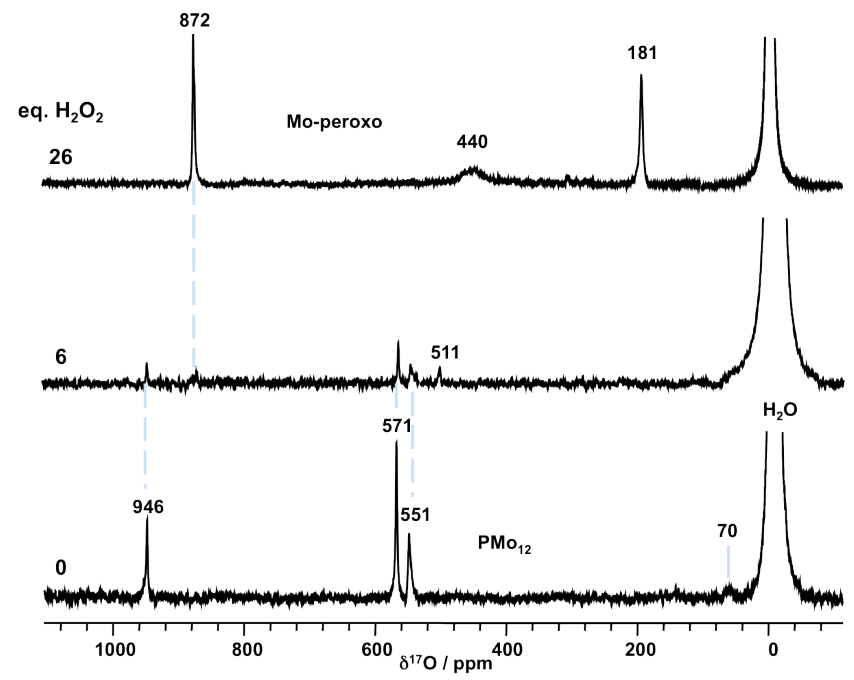

Fig. 7: ${ }^{17} \mathrm{O}$ NMR spectra of the Keggin anion $\left[\mathrm{PMo}_{12} \mathrm{O}_{40}\right]^{3-}$ in $\mathrm{H}_{2} \mathrm{O} / \mathrm{D}_{2} \mathrm{O}(58 \mathrm{mM})$, before and after adding 6, and 26 equivalents of $\mathrm{H}_{2} \mathrm{O}_{2}$.

This preliminary study allows the identification of the main reduced phosphomolybdate species produced from the Keggin $\mathrm{H}_{3}\left[\mathrm{PMo}_{12} \mathrm{O}_{40}\right]$ under reduction conditions and the molybdate and peroxomolybdate species formed in oxidation condition with $\mathrm{H}_{2} \mathrm{O}_{2}$. Table 2 summarizes their NMR characterization in comparison with the literature. These spectroscopic data will serve as references for identifying the main catalytic active species in the sequential oxidation process of cyclohexanone by POM and hydrogen peroxide that will be presented in next sections.

\section{Table 2}

NMR data $(\delta / \mathrm{ppm})$ in aqueous solution of main species formed upon transformation of $\mathrm{H}_{3}\left[\mathrm{PMo}_{12} \mathrm{O}_{40}\right]$ in presence of reducing or oxidant agent.

\begin{tabular}{|c|c|c|c|}
\hline Compound & ${ }^{31} \mathbf{P}$ & ${ }^{95} \mathrm{Mo}$ & ${ }^{17} \mathbf{O}$ \\
\hline \multicolumn{4}{|l|}{ Initial POM } \\
\hline$\left[\mathrm{PMo}_{12} \mathrm{O}_{40}\right]^{3-}\{\alpha-0\}$ & $-3.1^{\mathrm{a}}$ & 21 & $70 ; 551 ; 571 ; 946$ \\
\hline \multicolumn{4}{|l|}{ Reduced species } \\
\hline$\left[\mathrm{PMo}_{12} \mathrm{O}_{40}\right]^{5-}\{\alpha-\mathrm{II}\}$ & $-5.5^{\mathrm{a}}$ & & $514 ; 525 ; 900^{\mathrm{b}}$ \\
\hline$\left[\mathrm{PMo}_{12} \mathrm{O}_{40}\right]^{5-}\{\beta-\mathrm{II}\}$ & $-6.6^{\mathrm{c}}$ & & \\
\hline$\left[\mathrm{PMo}_{12} \mathrm{O}_{40}\right]^{7-}\{\alpha-\mathrm{IV}\}$ & $-4.0^{\mathrm{a}}$ & & \\
\hline$\left[\mathrm{PMo}_{12} \mathrm{O}_{40}\right]^{7-}\{\beta-\mathrm{IV}\}$ & $-12.5^{\mathrm{a}}$ & $307^{\mathrm{c}}$ & $70 ; 453 ; 515 ; 548 ; 555 ; 906 ; 929^{\circ}$ \\
\hline \multicolumn{4}{|l|}{ Peroxo species } \\
\hline $\mathrm{MoO}\left(\mathrm{O}_{2}\right)_{2}\left(\mathrm{H}_{2} \mathrm{O}\right)_{2}$ & & -191 & $440 ; 872$ \\
\hline $\mathrm{PO}_{4}\left[\mathrm{MoO}\left(\mathrm{O}_{2}\right)_{2}\right]_{4}{ }^{3-}\left\{\mathrm{PMo}_{4}\right\}$ & 3.5 & -242 & \\
\hline $\mathrm{PMo}_{3} \mathrm{O}_{\mathrm{m}}{ }^{\mathrm{n}-}\left\{\mathrm{PMo}_{3}\right\}$ & 2.0 & & \\
\hline $\mathrm{PO}_{4}\left[\mathrm{MoO}\left(\mathrm{O}_{2}\right)_{2}\right]_{2}{ }^{2-}\left\{\mathrm{PMO}_{2}\right\}$ & 0.4 & & \\
\hline
\end{tabular}




\subsection{Monitoring the state of the working catalyst}

\subsubsection{The first reduction stages}

It is known that $\mathrm{H}_{3}\left[\mathrm{PMo}_{12} \mathrm{O}_{40}\right]$ acid is highly soluble in many organic solvents. Thus, its behavior toward the cyclohexanone was examined by ${ }^{31} \mathrm{P}$ NMR analysis. A solution containing $30 \mathrm{mg} \mathrm{H}_{3}\left[\mathrm{PMo}_{12} \mathrm{O}_{40}\right]$ in $3 \mathrm{~mL}$ of cyclohexanone was maintained at $55{ }^{\circ} \mathrm{C}$ over a period of $20 \mathrm{~h}$ during the NMR measurements. The evolution of the spectra as a function of time is showed in Fig. 8. The spectrum of the solution as prepared within the first hour exhibits a main signal at -2.3 ppm corresponding to the starting oxidized POM $\{\alpha-0\}$, and a secondary resonance at ca. $-4.1 \mathrm{ppm}$ that could be due to the two electron reduced species $\{\alpha-$ II\}. This signal increased quickly during increasing temperature and then decreased until complete disappearance after a prolonged heating time. The main signal at $-2.3 \mathrm{ppm}$ gradually moved to ca. $-3.0 \mathrm{ppm}$ after $20 \mathrm{~h}$ of heating. This observation is interpreted as a result of fast interconversion exchange between two distinct species, most probably $\left[\mathrm{PMo}_{12} \mathrm{O}_{40}\right]^{3-}\{\alpha-0\}$ and $\left[\mathrm{PMo}_{12} \mathrm{O}_{40}\right]^{5-}\{\alpha-\mathrm{IV}\}$ based on the observed chemical shifts.

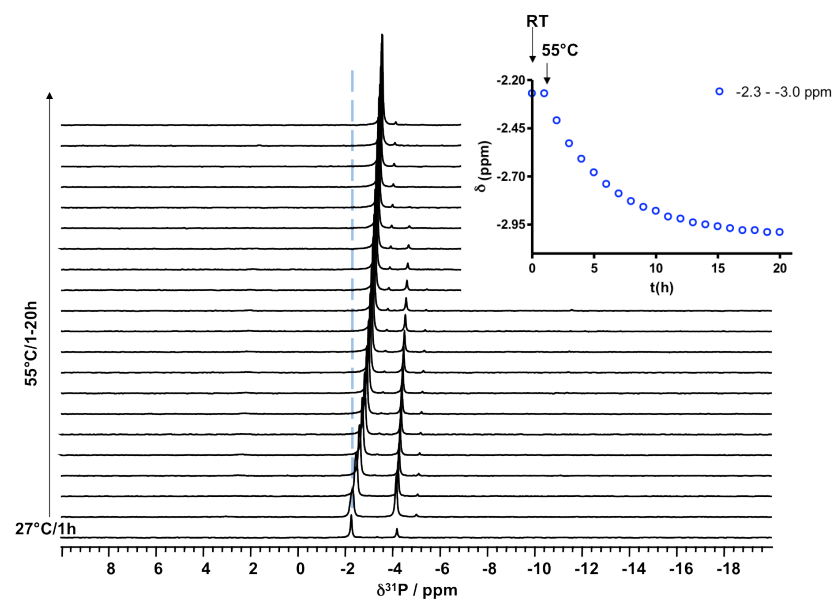

Fig. 8: Time-dependent ${ }^{31} \mathrm{P}$ NMR of a mixture of $30 \mathrm{mg} \mathrm{H}{ }_{3}\left[\mathrm{PMo}_{12} \mathrm{O}_{40}\right]+3 \mathrm{~mL}$ cyclohexanone at $55{ }^{\circ} \mathrm{C}$ over a period of $21 \mathrm{~h}$. Inset: Change in chemical shifts of main resonance $(-2.3--3.0 \mathrm{ppm})$.

The differences in chemical shifts of the species, $\{\alpha-0\},\{\alpha-I I\}$, and $\{\alpha-I V\}$, i.e., systematic 1-1.5 ppm low-field shift compared to previous study in 3.2 section are explained by the solvent effect, cyclohexanone medium versus pure aqueous or mixed aqueous-dioxane solutions. Furthermore, the sequential appearance of these signals is also consistent with the 
previously established shielding effect order, $\delta\{\alpha-0\}<\delta\{\alpha-\mathrm{IV}\}<\delta\{\alpha-\mathrm{II}\}$. The reduction of the POM is confirmed by the color change of the sample from yellow (starting oxidized POM) to dark blue at the end of the experiment, after $20 \mathrm{~h}$ at $55^{\circ} \mathrm{C}$. Such a phenomenon appeared much faster in cyclohexanone than in aqueous medium confirming the interaction between the catalyst and the substrate.

The second remarkable difference with the behavior of the aqueous solution is the intriguing fast exchange process between $\{\alpha-0\}$ and $\{\alpha-I V\}$. This four-electron reduced species is favored at high temperature and should be obtained through reduction from the twoelectron reduced species $\{\alpha-\mathrm{II}\}$. In an additional experiment without heating, one can see first almost complete conversion of $\{\alpha-0\}$ to $\{\alpha-\mathrm{II}\}$ after $6 \mathrm{~h}$ at $27^{\circ} \mathrm{C}$ (Fig. S1) and then only after heating at $55^{\circ} \mathrm{C}$ that $\{\alpha$-II $\}$ is transformed into $\{\alpha$-IV $\}$ after $15 \mathrm{~h}$ at $55^{\circ} \mathrm{C}$ (Fig. S2). Thus it is reasonable to assign the final signal at $-3 \mathrm{ppm}$ to $\{\alpha-\mathrm{IV}\}$.

\subsubsection{Effect of adding $\mathrm{H}_{2} \mathrm{O}_{2}$}

The behavior of POM under reduction and oxidation cycles was monitored by ${ }^{31} \mathrm{P}$ NMR analysis as a function of time. The first period consists of reducing $\left[\mathrm{PMo}_{12} \mathrm{O}_{40}\right]^{3-}\{\alpha-0\}$ (30 $\mathrm{mg}$ ) by cyclohexanone $(3 \mathrm{~mL})$, during which a color change from yellow to blue is observed. Then, $0.5 \mathrm{~mL}$ of $\mathrm{H}_{2} \mathrm{O}_{2}$ was added twice, first in the beginning of the second period of again 20 $\mathrm{h}$ at $55^{\circ} \mathrm{C}$ and in the beginning of the third period of $44 \mathrm{~h}$ at $55^{\circ} \mathrm{C}$. Fig. 9 shows the ${ }^{31} \mathrm{P}$ NMR spectra at the beginning and end of each period.

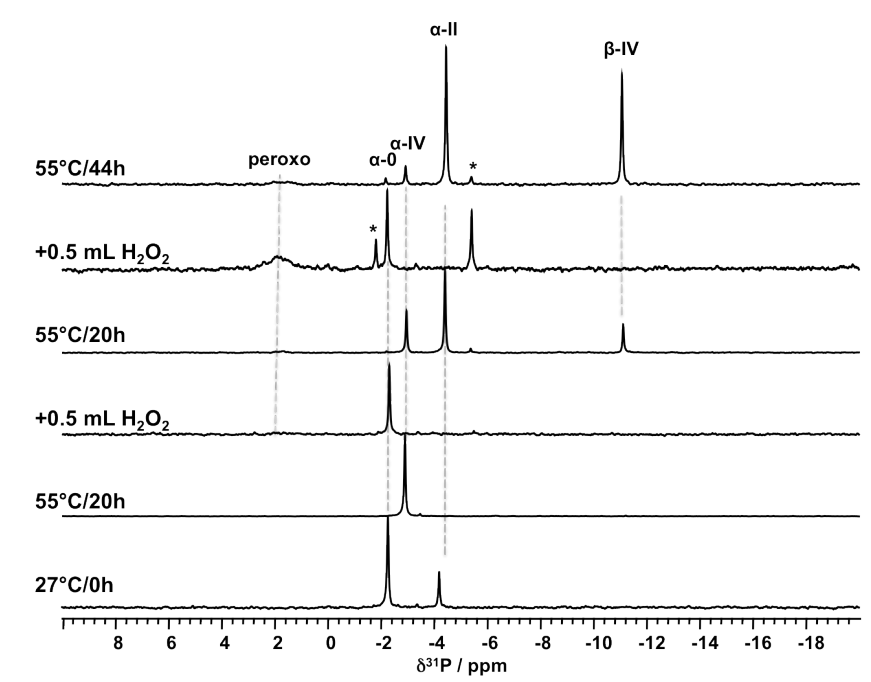

Fig. 9: Representative ${ }^{31} \mathrm{P} \mathrm{NMR}$ of a mixture of $30 \mathrm{mg} \mathrm{H}\left[\mathrm{PMo}_{12} \mathrm{O}_{40}\right]+3 \mathrm{~mL}$ cyclohexanone at $55{ }^{\circ} \mathrm{C}$ over a first period of $20 \mathrm{~h}$, followed by a subsequent addition of $0.5 \mathrm{~mL} \mathrm{H}_{2} \mathrm{O}_{2}$ over a period of $20 \mathrm{~h}$ at $55{ }^{\circ} \mathrm{C}$, and then a 
second addition of $0.5 \mathrm{~mL} \mathrm{H} \mathrm{O}_{2}$ over a period of $44 \mathrm{~h}$ at $55^{\circ} \mathrm{C}$. Note that $\mathrm{t}=0 \mathrm{~h}$ refers to NMR measurement starting after ca. $1 \mathrm{~h}$ of sample preparation. Asterisks (*) indicates unknown decomposition products, possibly lacunary Keggin POMs.

The complete series of spectra are shown in Fig. 8 for the first period, and in Supporting Information for the second and third periods (Figs. S3, and S4). The spectrum at the beginning of the first period is characterized as seen previously by the signals of $\{\alpha-0\}$ and $\{\alpha-\mathrm{II}\}\left(-2.3\right.$ and $-4.1 \mathrm{ppm}$, respectively). After $20 \mathrm{~h}$ at $55^{\circ} \mathrm{C}$, the main species left is the fourelectron reduced $\{\alpha-\mathrm{IV}\}(-3.0 \mathrm{ppm})$. Addition of $\mathrm{H}_{2} \mathrm{O}_{2}$ solution restores the initial signal at $2.3 \mathrm{ppm}$ of the starting oxidized form $\{\alpha-0\}$. After further reaction at $55{ }^{\circ} \mathrm{C}$ for $20 \mathrm{~h}$, reduced species $\{\alpha-\mathrm{II}\}$ and $\{\alpha-\mathrm{IV}\}$ reappeared again, but accompanied also by the formation of $\{\beta-$ IV \}. Interestingly enough, this latter species appeared only after intervention of water in the cyclohexanone oxidation. Furthermore, in presence of water the two species $\{\alpha-0\}$ and $\{\alpha-$ IV \} will coexist in slow chemical exchange. The second $\mathrm{H}_{2} \mathrm{O}_{2}$ addition at the end of this second period, allowed conversion of all reduced species, not only into the starting oxidized POM $\{\alpha-0\}$, but also to some decompositions products and peroxo complexes characterized by low-field signals in the range $2-3 \mathrm{ppm}$. These results would also indicate that peroxo complexes play a key role in catalytic oxidative cyclohexanone conversion.

Quantitative analysis of the NMR data offers a way to follow the evolution of catalytic species. Fig. 10 displays the distribution of the different forms of the catalyst in their evolving medium during the three successive periods studied, i) the reduction in cyclohexanone, ii) first and iii) second subsequent reoxidation by $\mathrm{H}_{2} \mathrm{O}_{2}$. The proportions of species are determined from NMR integration of the corresponding signals. In the case of fast chemical exchange between species $\{\alpha-0\}$ and $\{\alpha-I V\}$ in the first period, their relative proportion are determined from the observed chemical shift $\left(\delta_{\mathrm{obs}}=\mathrm{x} \delta_{\{\alpha-0\}}+(1-\mathrm{x}) \delta_{\{\alpha-\mathrm{IV}\}}\right)$. During the first period (the reduction by cyclohexanone), one can see the continuous decrease of both oxidized and twoelectron reduced species $\{\alpha-0\}$ and $\{\alpha-\mathrm{II}\}$ in favor of the four-electron reduced species $\{\alpha-$ IV $\}$ that becomes the prominent form after $20 \mathrm{~h}$ of reaction at $55{ }^{\circ} \mathrm{C}$. This observation confirms that this latter is formed most probably from conversion of both $\{\alpha-\mathrm{II}\}$ and species $\{\alpha-0\}$ directly. Furthermore, significant NMR signal loss is noticed (up to 25\%) that should account for other non-detected phosphorus-based species. Such species could represent paramagnetic intermediates with one or three electron reduction. In period $\mathrm{II}, \mathrm{H}_{2} \mathrm{O}_{2}$ addition 
led to the oxidized species $\{\alpha-0\}$ but not quantitatively, where less than $20 \%$ of initial quantity is only observed. The remaining undetected fraction probably corresponds to paramagnetic species. After $5 \mathrm{~h}$ at $55^{\circ} \mathrm{C}$, the first reduced species formed are $\{\alpha$-II $\}$ followed few hours later by $\{\alpha-I V\}$ and $\{\beta-I V\}$. Note the formation of peroxo species in very few amounts at prolonged reaction time. After the second addition of $\mathrm{H}_{2} \mathrm{O}_{2}$ (period III), similar observations took place, i.e., formation of large amount of undetected species, regeneration of oxidized species $\{\alpha-0\}$, and appearance of peroxo species in significant amount. This latter decreased quickly with time at the expense of the $\{\alpha-0\}$ species, that in its turn decreased few hours later in favor of four-electron reduced species $\{\alpha-I V\}$ and $\{\beta-I V\}$. Note that the $\{\beta-I V\}$ continued to increase and $\{\alpha-\mathrm{IV}\}$ continued to decrease. This clearly indicates that the final stable four-electron reduced species should be the $\beta$-isomer as it appears much later. 

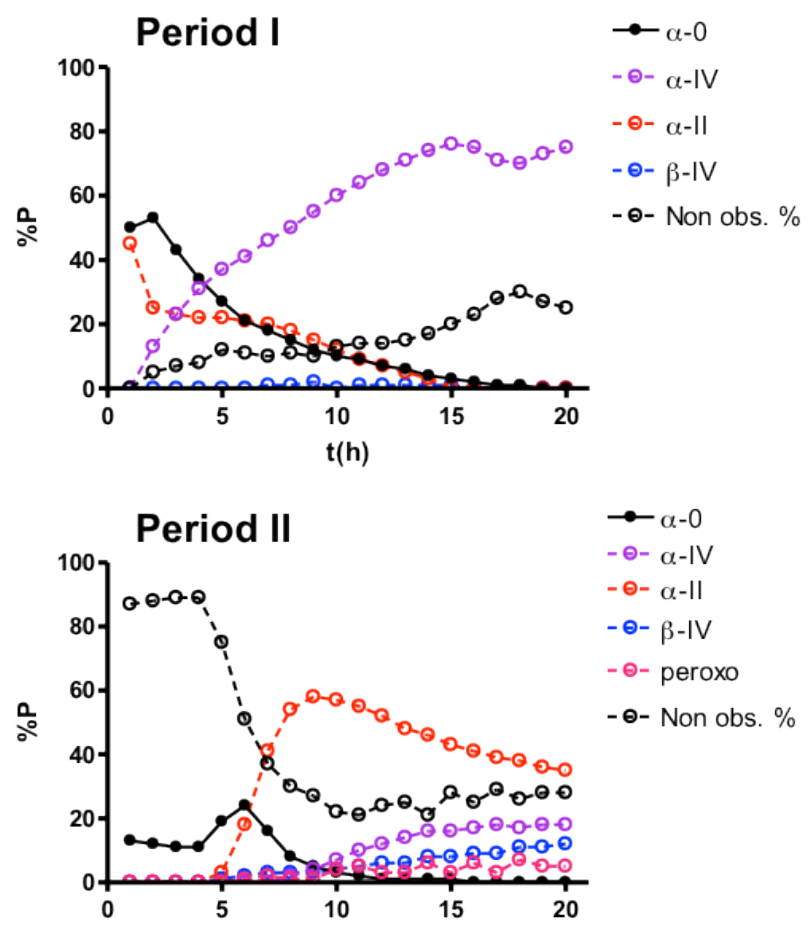

$-\theta-\alpha-I I$

$-\theta-\beta-I V$

- ๑- peroxo

- $\bullet$ - Non obs. \%

$\mathrm{t}(\mathrm{h})$

$\rightarrow \alpha-0$

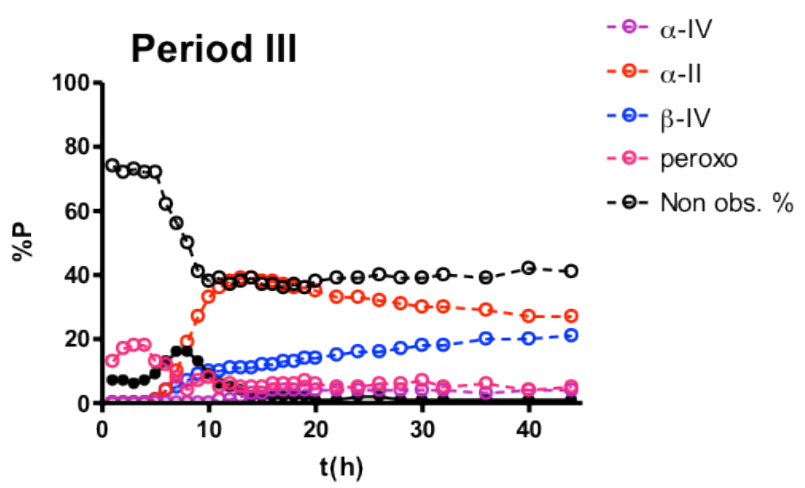

Fig. 10: Phosphorus species distribution based on ${ }^{31} \mathrm{P}$ NMR in a mixture of $30 \mathrm{mg} \mathrm{H}_{3}\left[\mathrm{PMo}_{12} \mathrm{O}_{40}\right]+3 \mathrm{~mL}$ cyclohexanone at $55^{\circ} \mathrm{C}$ over a period of $20 \mathrm{~h}$ (period I), followed by a subsequent addition of $0.5 \mathrm{~mL} \mathrm{H}_{2} \mathrm{O}_{2}$ over a period of $20 \mathrm{~h}$ at $55^{\circ} \mathrm{C}$ (period II), and then a second addition of $0.5 \mathrm{~mL} \mathrm{H} \mathrm{O}_{2}$ over a period of $44 \mathrm{~h}$ at $55^{\circ} \mathrm{C}$ (period III).

\subsubsection{Effect of water}

Another similar series of experiments have been performed with $\mathrm{D}_{2} \mathrm{O} .300 \mathrm{mg}$ of $\mathrm{H}_{3}\left[\mathrm{PMo}_{12} \mathrm{O}_{40}\right]$ are dissolved in a mixture of $2.5 \mathrm{~mL} \mathrm{D} 2 \mathrm{O}$ and $0.5 \mathrm{~mL}$ cyclohexanone. The system is now biphasic because of the immiscibility of cyclohexanone with water. Fig. 11 shows some selected spectra of ${ }^{31} \mathrm{P}$ NMR analysis of reaction mixture. The complete series of spectra corresponding to the reduction of $\left[\mathrm{PMo}_{12} \mathrm{O}_{40}\right]^{3-}$ by cyclohexanone at $55{ }^{\circ} \mathrm{C}$ over a period of $16.5 \mathrm{~h}$ and subsequent addition of $0.5 \mathrm{~mL} \mathrm{H}_{2} \mathrm{O}_{2}$ and reaction at $55^{\circ} \mathrm{C}$ for $17.5 \mathrm{~h}$ are 
shown respectively in Figs. S5 and S6 of Supporting Information. In this system, the same species are observed with $\mathrm{D}_{2} \mathrm{O}$, except the signal of species $\{\alpha-\mathrm{IV}\}$ that was not detected. The signals of species $\{\alpha-0\},\{\alpha-\mathrm{II}\}$, and $\{\beta-\mathrm{IV}\}$ appeared doubled because of two phases, aqueous and organic. It is interesting to note the formation of the four-electron reduced species $\{\beta-\mathrm{IV}\}$ already in the first reduction period in absence of intermediate species $\{\alpha$ IV \}. This observation has already been seen in pure aqueous system (see Fig. 4), where the transition $\{\alpha-\mathrm{IV}\} \rightarrow\{\beta-\mathrm{IV}\}$ was too fast to be detected. One could conclude, therefore, the isomer $\{\alpha-\mathrm{IV}\}$ is stabilized to some extent in the organic phase. The second interesting remark concerns the ease of peroxo species formation upon $\mathrm{H}_{2} \mathrm{O}_{2}$ addition. This would indicate peroxo species are more favored in aqueous medium than in organic substrate environment.

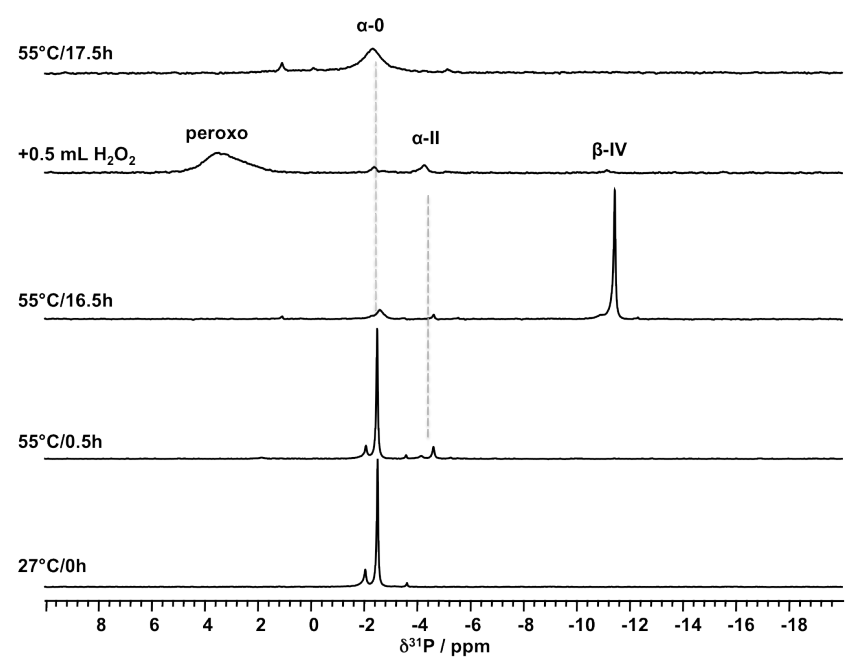

Fig. 11: Representative ${ }^{31} \mathrm{P}$ NMR of a mixture of $300 \mathrm{mg} \mathrm{H} \mathrm{H}_{3}\left[\mathrm{PMo}_{12} \mathrm{O}_{40}\right]+2.5 \mathrm{~mL} \mathrm{H}_{2} \mathrm{O}+0.5 \mathrm{~mL}$ cyclohexanone at $55{ }^{\circ} \mathrm{C}$ over a first period of $16.5 \mathrm{~h}$, and then after addition of $0.5 \mathrm{~mL} \mathrm{H}_{2} \mathrm{O}_{2}$ over a second period of $17.5 \mathrm{~h}$ at 55 ${ }^{\circ} \mathrm{C}$.

In Fig. 12, one can see the distribution of $\mathrm{H}_{3}\left[\mathrm{PMo}_{12} \mathrm{O}_{40}\right]$ species in the system $\mathrm{D}_{2} \mathrm{O}$ cyclohexanone $(\mathrm{v} / \mathrm{v}: 5 / 1)$ at $55{ }^{\circ} \mathrm{C}$, before and after $\mathrm{H}_{2} \mathrm{O}_{2}$ addition. The curves indicate that $\left[\mathrm{PMo}_{12} \mathrm{O}_{40}\right]^{3-}\{\alpha-0\}$ transforms to $\left[\mathrm{PMo}_{12} \mathrm{O}_{40}\right]^{5-}\{\alpha-\mathrm{II}\}$ that transforms later to $\left[\mathrm{PMo}_{12} \mathrm{O}_{40}\right]^{7-}$ $\{\beta-\mathrm{IV}\}$. This sequence is similar to that observed previously in water (Fig. 4). Note that here again ca. $20 \%$ of the initial signal is missing, that is indicative of some non-detected paramagnetic species. Addition of hydrogen peroxide leads mainly to peroxo species which decrease slowly with time to produce the starting oxidized POM, $\left[\mathrm{PMo}_{12} \mathrm{O}_{40}\right]^{3-}\{\alpha-0\}$. This proves the reversible transformation of Keggin POMs to peroxomolybdate complexes under 
the catalytic conditions. No reduced species have been observed in these conditions up to $18 \mathrm{~h}$ of reaction, but a quite large amount of undetectable species was measured.
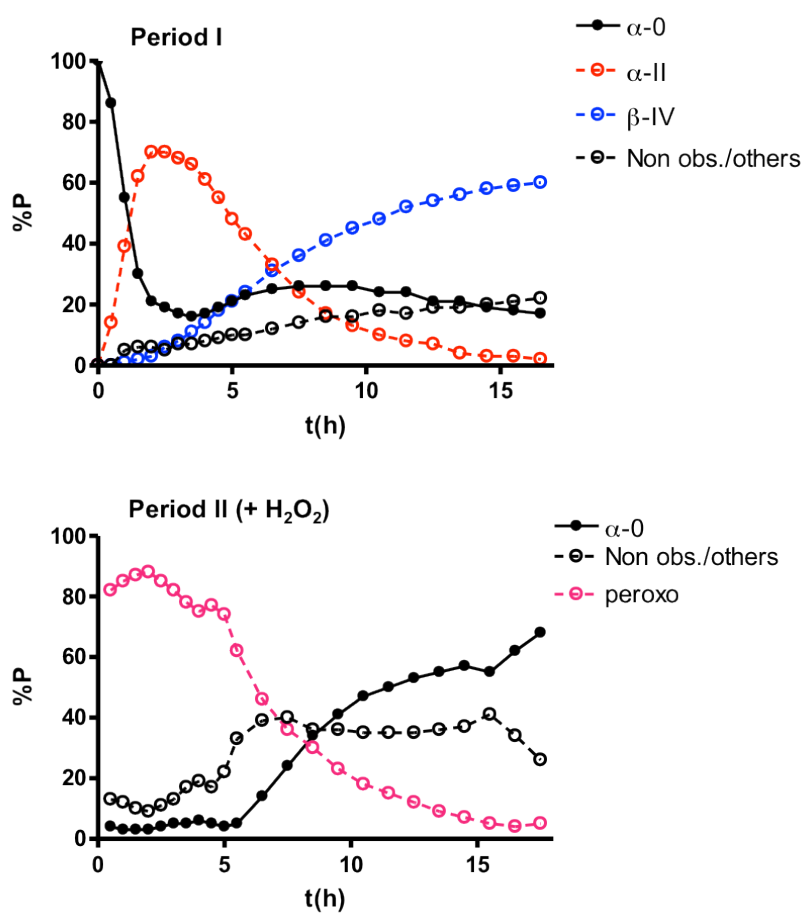

Fig. 12: Phosphorus species distribution based on ${ }^{31} \mathrm{P}$ NMR in a mixture of $300 \mathrm{mg} \mathrm{H}_{3}\left[\mathrm{PMo}_{12} \mathrm{O}_{40}\right]+2.5 \mathrm{~mL} \mathrm{H}_{2} \mathrm{O}$ $+0.5 \mathrm{~mL}$ cyclohexanone at $55{ }^{\circ} \mathrm{C}$ over a period of $16.5 \mathrm{~h}$ (period I), and after subsequent addition of $0.5 \mathrm{~mL}$ $\mathrm{H}_{2} \mathrm{O}_{2}$ over a period of $17.5 \mathrm{~h}$ at $55^{\circ} \mathrm{C}($ period II).

\subsection{Activation of the substrate}

The substrate behavior during the catalytic reaction was checked by ${ }^{1} \mathrm{H}$ NMR analysis in parallel to ${ }^{31} \mathrm{P}$ NMR. A stack plot of ${ }^{1} \mathrm{H}$ NMR spectra of a solution of $30 \mathrm{mg} \mathrm{H} \mathrm{H}_{3}\left[\mathrm{PMo}_{12} \mathrm{O}_{40}\right]$ in $3 \mathrm{~mL}$ cyclohexanone is presented in Fig. 13 showing the spectral evolution with time at 55 ${ }^{\circ} \mathrm{C}$. The spectra are characterized by the three dominant resonances of cyclohexanone in the range 2.2-2.8 ppm and a signal of residual water from the catalyst. This latter underwent a significant high-field shift from ca. 5 to $3.8 \mathrm{ppm}$ when the temperature increases from 27 to $55^{\circ} \mathrm{C}$. Very early just after heating, new resonances appeared and grew with time at 2.0, 2.3, $2.4,3.3$, and $5.8 \mathrm{ppm}$. The resonance at $5.8 \mathrm{ppm}$ falls in typical ethylenic protons resonance range and allows assigning the new resonance lines to tautomeric enol-form of cyclohexanone. Such a tautomerism between cyclohexanone and the corresponding enolic 
form has been reported and it is suggested that it represents the activation step for the oxidation of cyclohexanone [33, 61].

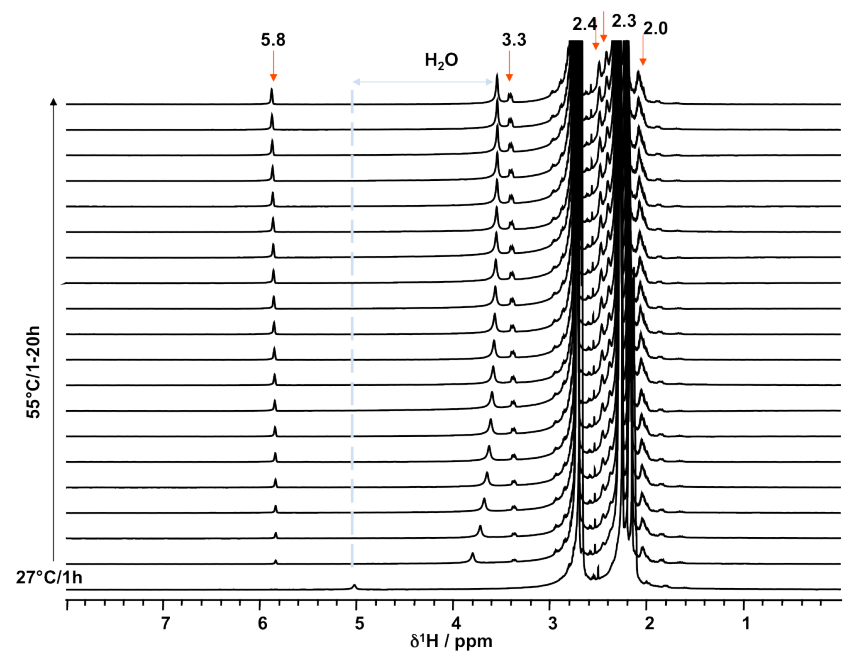

Fig. 13: Time-dependent ${ }^{1} \mathrm{H}$ NMR of a mixture of $30 \mathrm{mg} \mathrm{H} \mathrm{H}_{3}\left[\mathrm{PMo}_{12} \mathrm{O}_{40}\right]+3 \mathrm{~mL}$ cyclohexanone at $55{ }^{\circ} \mathrm{C}$ over a period of $20 \mathrm{~h}$.

No other ${ }^{1} \mathrm{H}$ resonances than those of keto-enol tautomers of cyclohexanone has been detected in presence of $\mathrm{H}_{3}\left[\mathrm{PMo}_{12} \mathrm{O}_{40}\right]$ over a period of $20 \mathrm{~h}$ at $55{ }^{\circ} \mathrm{C}$. Addition of $\mathrm{H}_{2} \mathrm{O}_{2}$ had however led to the appearance of novel signals at 1.2, 1.6, 3.9 and $10 \mathrm{ppm}$, indicating products formation of the first oxidation (Fig. 14). In particular, the weak deshielded resonance at ca. $10 \mathrm{ppm}$ that could represent carboxylic acid protons (observable in organic phase). This would indicate that formation of adipic acid is initiated only after addition of hydrogen peroxide, and the POM alone is not able to cleave the $\mathrm{C}-\mathrm{C}$ bound of the organic substrate in these conditions.

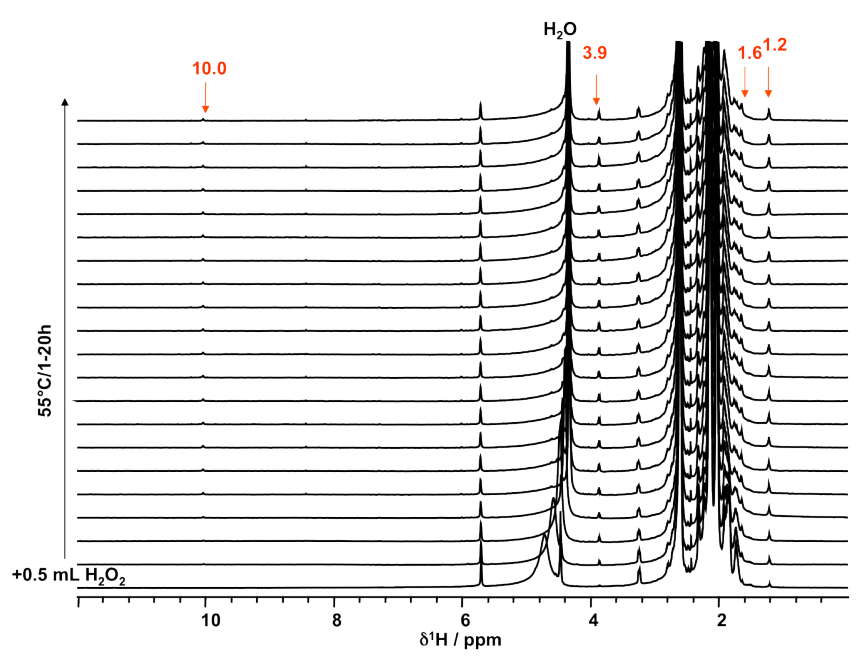


Fig. 14: Time-dependent ${ }^{1} \mathrm{H}$ NMR of a mixture of $30 \mathrm{mg} \mathrm{H}\left[\mathrm{PMo}_{12} \mathrm{O}_{40}\right]+3 \mathrm{~mL}$ cyclohexanone at $55{ }^{\circ} \mathrm{C}$ over a period of $20 \mathrm{~h}$, after adding $0.5 \mathrm{~mL} \mathrm{H}_{2} \mathrm{O}_{2}$ subsequently to a first period of $20 \mathrm{~h}$ at $55{ }^{\circ} \mathrm{C}$ (shown in Fig. 13).

To further evidence the tautomerism reaction an $\mathrm{H} / \mathrm{D}$ exchange experiment has been conducted and monitored in situ by ${ }^{1} \mathrm{H}$ NMR. A mixture constituted of $30 \mathrm{mg} \mathrm{H}_{3}\left[\mathrm{PMo}_{12} \mathrm{O}_{40}\right]$ $+0.5 \mathrm{~mL}$ cyclohexanone $+2.5 \mathrm{D}_{2} \mathrm{O}$ is heated at $55^{\circ} \mathrm{C}$ over a period of $17.5 \mathrm{~h} .{ }^{1} \mathrm{H}$ NMR does not show the appearance of new resonance lines, but a change in integration of the initial signals as a result of $\mathrm{H} / \mathrm{D}$ substitution (Fig. 15).

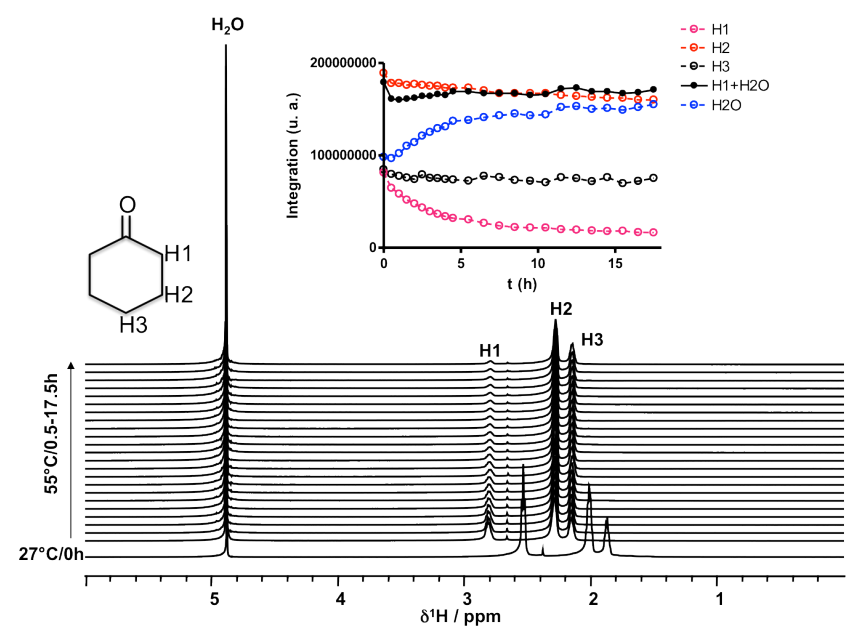

Fig. 15: Time-dependent ${ }^{1} \mathrm{H}$ NMR of a mixture of $30 \mathrm{mg} \mathrm{H} \mathrm{H}_{3}\left[\mathrm{PMo}_{12} \mathrm{O}_{40}\right]+2.5 \mathrm{~mL} \mathrm{D} \mathrm{D}_{2} \mathrm{O}+0.5 \mathrm{~mL}$ cyclohexanone at $55^{\circ} \mathrm{C}$ over a period of $20 \mathrm{~h}$. Inset: Evolution in signal integration of $\mathrm{H} 1, \mathrm{H} 2, \mathrm{H} 3, \mathrm{H}_{2} \mathrm{O}$, and $\mathrm{H} 1+\mathrm{H}_{2} \mathrm{O}$. Note that this latter is nearly constant during all experimental time.

The initial spectrum showed the three resonance peaks of the cyclohexanone, from low to high-field $\mathrm{H} 1, \mathrm{H} 2$, and $\mathrm{H} 3$ for $\alpha$-, $\beta$-, and $\gamma$-position respectively (see Fig. 15), as well as the signal of water at ca. $4.8 \mathrm{ppm}$. A temperature increase leads to a shift of all the cyclohexanone signals to a low field domain, a sharp decrease in the signal integration of the resonance H1 ( $\alpha$-position), and simultaneously to an increase of the water signal of water. The signals intensities of the other protons vary a little. This is a clear indication of H/D exchange between the deuterium of water and the H1 of cyclohexanone. Such a process needs necessarily a tautomeric equilibrium to explain the $\mathrm{H} 1$ lability in the molecule according to the process drawn in Scheme 1. The signal loss of $\mathrm{H} 1$ reaches below $10 \%$ of its initial integration (Fig. 16). This process occurs also at room temperature but with much slower rate, i.e., one order on magnitude lower (Figs. S7 and S8). The tautomerism equilibrium should be catalyzed by acidic protons provided by the POM. Indeed, when the same experiment is 
conducted in the absence of the POM, i.e., $0.5 \mathrm{~mL}$ cyclohexanone $+2.5 \mathrm{D}_{2} \mathrm{O}$ (Fig. S9), no $\mathrm{H} / \mathrm{D}$ exchange reaction occurs throughout the period of $18 \mathrm{~h}$ at $55{ }^{\circ} \mathrm{C}$. This result clearly indicates the need of the POM presence as acidic proton source to activate the substrate.

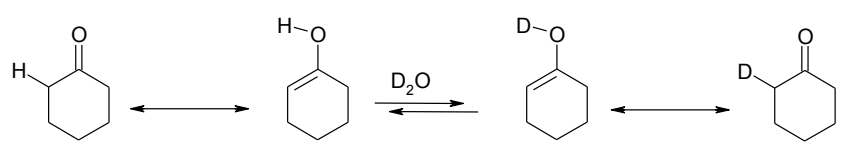

Scheme 1: Ketonic-enolic tautomerism in cyclohexanone and regioselective H/D exchange.
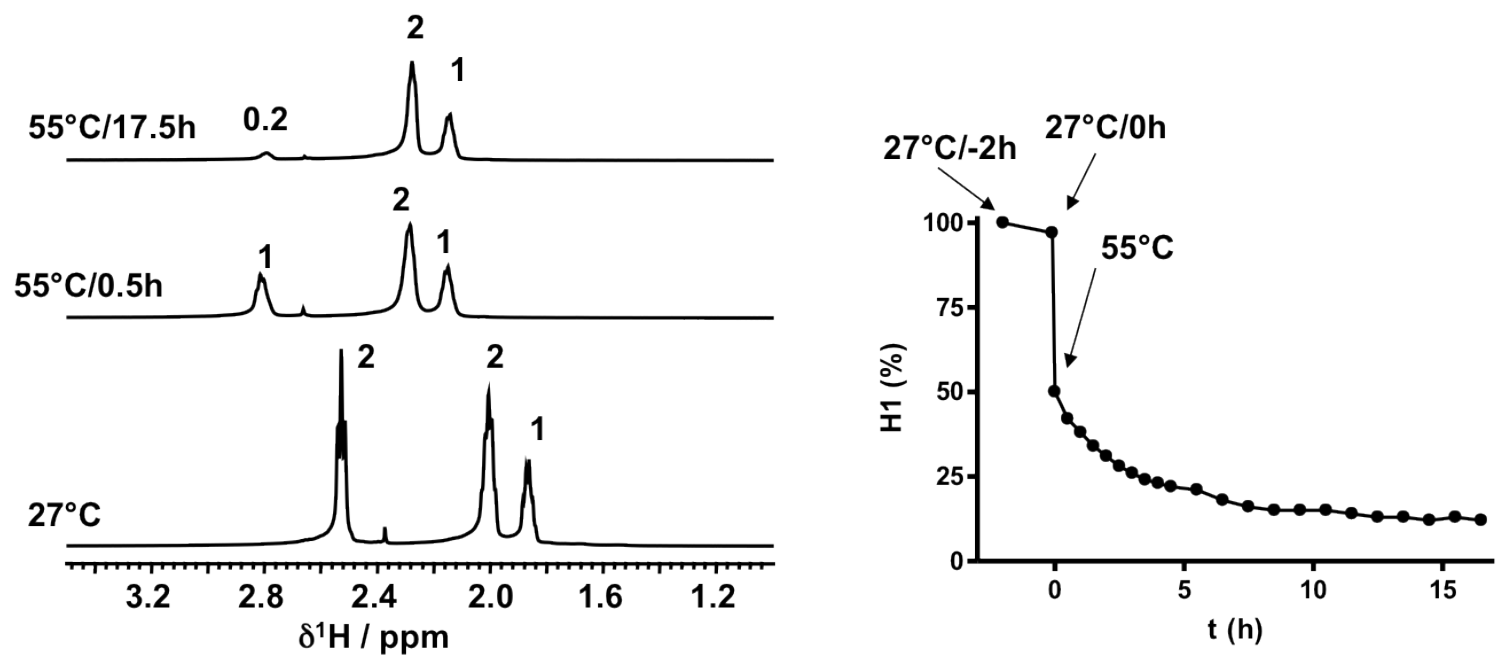

Fig. 16: Left: Selected ${ }^{1} \mathrm{H}$ NMR spectra of cyclohexanone in the mixture of $30 \mathrm{mg} \mathrm{H} \mathrm{H}_{3}\left[\mathrm{PMo}_{12} \mathrm{O}_{40}\right]+2.5 \mathrm{~mL} \mathrm{D}_{2} \mathrm{O}$ $+0.5 \mathrm{~mL}$ cyclohexanone. The number on the top of each signal indicates the relative signal area. Right: Evolution of $\mathrm{H} 1$ signal integration as a function of time at $55^{\circ} \mathrm{C}$.

\subsection{Mechanism of cyclohexanone activation and oxidative conversion}

Based on current obtained results, a proposed mechanism of the cyclohexanone activation and conversion in presence of water and $\mathrm{H}_{2} \mathrm{O}_{2}$, after the third addition of $\mathrm{H}_{2} \mathrm{O}_{2}$, is shown in Scheme 2. The first step consists of activation of the cyclohexanone molecule through ketonic-enolic tautomerism and the enolic form undergoes readily an oxidation by a peroxomolybdate complex, leading to 2-hydroxy cyclohexanone. The tautomerism equilibrium is accelerated by the catalytic acid action of the heteropolyacid, $\mathrm{H}_{3}\left[\mathrm{PMo}_{12} \mathrm{O}_{40}\right]$, that facilitates the subsequent oxidation reaction through an epoxy derivative intermediate. The peroxo catalyst is regenerated in its most stable form by the hydrogen peroxide. As it has been shown by our in situ NMR experiments, peroxomolybdate species are formed in situ during decomposition of the Keggin $\left[\mathrm{PMo}_{12} \mathrm{O}_{40}\right]^{3-}$ by $\mathrm{H}_{2} \mathrm{O}_{2}$ in aqueous solution, and had also 
been suggested as active species in previous studies [62]. In the last steps, intermediate species would undergo further oxidation to probably lead to adipic anhydride, which can be readily hydrolyzed. Similar mechanism has also been proposed recently [63]. Further investigations are needed to determine the nature of the intermediates and to reveal the precise structure of the peroxo-type catalyst. Unfortunately, in contrast to aqueous solutions, ${ }^{95} \mathrm{Mo}$ NMR failed in cyclohexanone media and no signal could be measured probably due to severe linewidth broadening. Also, ${ }^{17} \mathrm{O}$ NMR showed only the signal of cyclohexanone $(\delta=560$ ppm), while the catalyst was difficult to detect because it was too dilute.

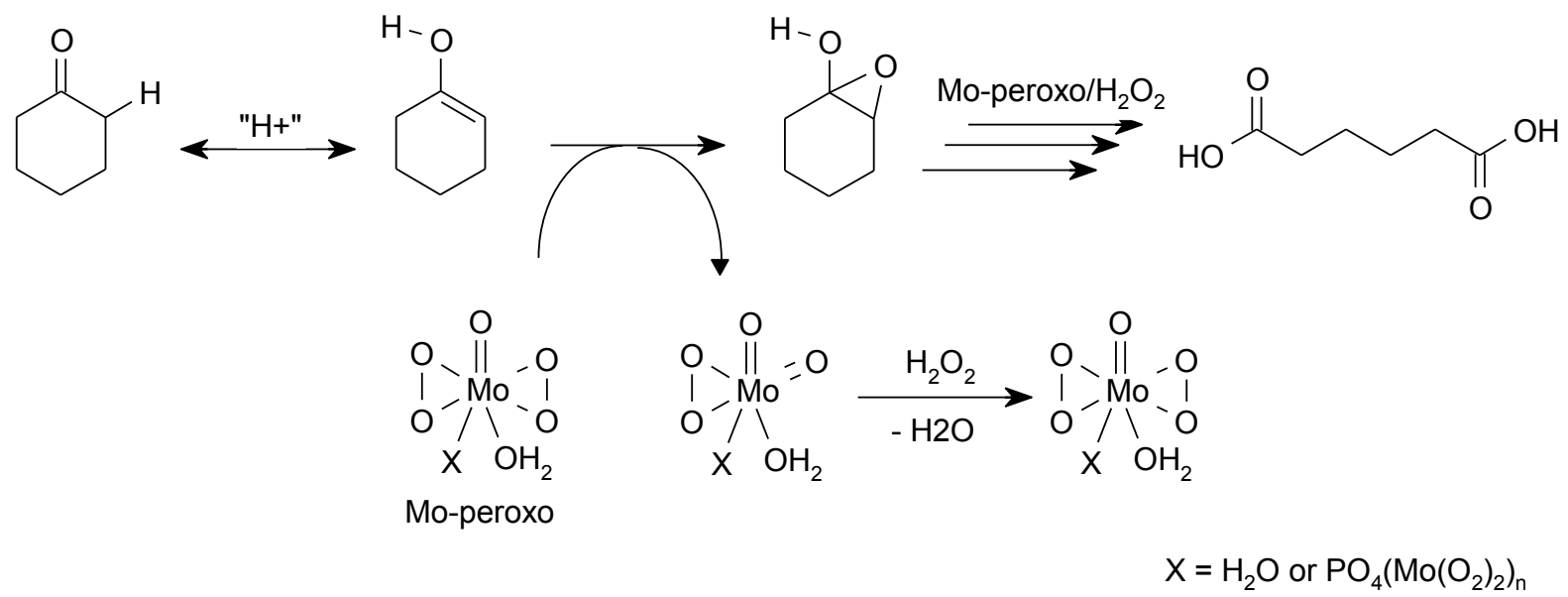

Scheme 2: Proposed mechanism of oxidative conversion of cyclohexanone by peroxomolybdate species. The formal charge on the peroxo Mo complex is omitted for simplicity.

\section{Conclusion}

In this report, the catalytic behavior of the Keggin $\mathrm{H}_{3}\left[\mathrm{PMo}_{12} \mathrm{O}_{40}\right]$ in oxidation of cyclohexanone by $\mathrm{H}_{2} \mathrm{O}_{2}$ has been investigated in situ by multinuclear NMR spectroscopy. Time-dependent NMR spectra of the working catalyst were recorded at moderate temperature in order to monitor the early stages of the catalytic processes. In the absence of oxidant agent, i.e., $\mathrm{H}_{2} \mathrm{O}_{2}$, the POM is reduced to $\alpha-\left[\mathrm{PMo}_{12} \mathrm{O}_{40}\right]^{5-}$ first then to $\alpha-\left[\mathrm{PMo}_{12} \mathrm{O}_{40}\right]^{7-}$ and finally isomerizes into $\beta-\left[\mathrm{PMo}_{12} \mathrm{O}_{40}\right]^{7-}$ only in presence of water at $55{ }^{\circ} \mathrm{C}$. During these processes cyclohexanone did not undergo substantial oxidation, but was subjected to keton-enol tautomerisation catalyzed by the Brønsted acidity of the POM. This tautomeric equilibrium can be seen as a key step for activation of the substrate for oxidation reaction. Under the effect of hydrogen peroxide the Keggin structure decomposes progressively into lacunary 
species first, and then to peroxo-type molybdenum complexes, including peroxophosphomolydate $\mathrm{PMo}_{n}$ complexes $(n=3,4)$. These species are responsible of the catalytic oxidative conversion of cyclohexanone into carboxylic acids. A three-step mechanism is proposed to explain the successive oxidation of the cyclohexanone by the peroxomolybdates species. The current studies provided some useful insights about the catalyst states change during the process, but further investigation is still needed to provide the complete scenario in particular concerning the non-observed NMR fraction of paramagnetic species.

\section{Acknowledgments}

This research is supported by the University of Versailles St-Quentin en Yvelines and the Centre National de la Recherche Scientifique.

\section{References}

[1] M. Freemantle, Chem. Eng. News 78 (2000) 7.

[2] J.A. Glaser, Clean Technol. Environ. Policy 18 (2016) 983.

[3] N. d'Alessandro, L. Liberatore, L. Tonucci, A. Morvillo, M. Bressan, New J. Chem. 25 (2001) 1319.

[4] N.V. Maksimchuk, K.A. Kovalenko, V.P. Fedin, O.A. Kholdeeva, Chem. Commun. 48 (2012) 6812.

[5] R. Noyori, M. Aoki, K. Sato, Chem. Commun. (2003) 1977.

[6] I.Q. Penate, G. Lesage, P. Cognet, M. Poux, Chem. Eng. J. 200 (2012) 357.

[7] B.M. Trost, Angew. Chem.-Int. Edit. Engl. 34 (1995) 259.

[8] M. Vafaeezadeh, M.M. Hashemi, Chem. Eng. J. 221 (2013) 254.

[9] Y.Q. Wen, X.Y. Wang, H.J. Wei, B.J. Li, P. Jin, L.M. Li, Green Chem. 14 (2012) 2868.

[10] J.M. Campos-Martin, G. Blanco-Brieva, J.L.G. Fierro, Angew. Chem.-Int. Edit. 45 (2006) 6962.

[11] A. Castellan, J.C.J. Bart, S. Cavallaro, Catal. Today 9 (1991) 255.

[12] A. Rahman, M. Mupa, C. Mahamadi, Catal. Lett. 146 (2016) 788.

[13] S. Van de Vyver, Y. Roman-Leshkov, Catal. Sci. Technol. 3 (2013) 1465.

[14] A. Castellan, J.C.J. Bart, S. Cavallaro, Catal. Today 9 (1991) 285.

[15] A.V. Leont'ev, O.A. Fomicheva, M.V. Proskurnina, N.S. Zefirov, Uspekhi Khimii 70 (2001) 107.

[16] J. Perez-Ramirez, F. Kapteijn, K. Schoffel, J.A. Moulijn, Appl. Catal. B-Environ. 44 (2003) 117.

[17] A. Banerjee, B.S. Bassil, G.V. Roschenthaler, U. Kortz, Chem. Soc. Rev. 41 (2012) 7590.

[18] X.J. Feng, Y.G. Li, Z.M. Zhang, E. Wang, Acta Chim. Sin. 71 (2013) 1575.

[19] K. Nomiya, Y. Sakai, S. Matsunaga, Eur. J. Inorg. Chem. (2011) 179.

[20] A. Proust, B. Matt, R. Villanneau, G. Guillemot, P. Gouzerh, G. Izzet, Chem. Soc. Rev. 41 (2012) 7605.

[21] D.E. Katsoulis, Chem. Rev. 98 (1998) 359. 
[22] K. Nomiya, K. Ohta, Y. Sakai, T. Hosoya, A. Ohtake, A. Takakura, S. Matsunaga, Bull. Chem. Soc. Jpn. 86 (2013) 800.

[23] J. Alcaniz-Monge, G. Trautwein, A. Garcia-Garcia, J. Mol. Catal. A-Chem. 394 (2014) 211.

[24] S. Benadji, T. Mazari, L. Dermeche, N. Salhi, E. Cadot, C. Rabia, Catal. Lett. 143 (2013) 749.

[25] S.B. Jing, Z.L. Wang, W.C. Zhu, J.Q. Guan, G.J. Wang, React. Kinet. Catal. Lett. 89 (2006) 55.

[26] H.Y. Lu, W.Z. Ren, P.F. Liu, S.X. Qi, W.H. Wang, Y.M. Feng, F.X. Sun, Y.W. Wang, Appl. Catal. A-Gen. 441 (2012) 136.

[27] M. Vazylyev, D. Sloboda-Rozner, A. Haimov, G. Maayan, R. Neumann, Top. Catal. 34 (2005) 93.

[28] B.G. Donoeva, T.A. Trubitsina, G.M. Maksimov, R.I. Maksimovskaya, O.A. Kholdeeva, Eur. J. Inorg. Chem. (2009) 5142.

[29] O.A. Kholdeeva, R.I. Maksimovskaya, J. Mol. Catal. A-Chem. 262 (2007) 7.

[30] A. Lesbani, Sumiati, Mardiyanto, N.A. Fithri, R. Mohadi, Makara J. Sci. 19 (2015) 85.

[31] J.L. She, Z.H. Fu, J.W. Li, B. Zeng, S.P. Tang, W.F. Wu, H.H. Zhao, D.L. Yin, S.R. Kirk, Appl. Catal. B-Environ. 182 (2016) 392.

[32] J.M. Bregeault, M. Vennat, L. Salles, J.Y. Piquemal, Y. Mahha, E. Briot, P.C. Bakala, A. Atlamsani, R. Thouvenot, J. Mol. Catal. A-Chem. 250 (2006) 177.

[33] F. Cavani, L. Ferroni, A. Frattini, C. Lucarelli, A. Mazzini, K. Raabova, S. Alini, P. Accorinti, P. Babini, Appl. Catal. A-Gen. 391 (2011) 118.

[34] R. Neumann, A.M. Khenkin, Chem. Commun. (2006) 2529.

[35] S.A. Chavan, D. Srinivas, P. Ratnasamyi, J. Catal. 212 (2002) 39.

[36] M. Haouas, J. Trébosc, C. Roch-Marchal, E. Cadot, F. Taulelle, C. Martineau-Corcos, Magn. Reson. Chem. 55 (2017) 902.

[37] H. Shi, J.A. Lercher, X.Y. Yu, Catal. Sci. Technol. 5 (2015) 3035.

[38] T. Blasco, Chem. Soc. Rev. 39 (2010) 4685.

[39] Ivanova, II, Y.G. Kolyagin, Chem. Soc. Rev. 39 (2010) 5018.

[40] L. Zhang, Y.H. Ren, B. Yue, H.Y. He, Chem. Commun. 48 (2012) 2370.

[41] S. Walspurger, A. Goeppert, M. Haouas, J. Sommer, New J. Chem. 28 (2004) 266.

[42] C. Ammann, P. Meier, A.E. Merbach, J. Magn. Reson. 46 (1982) 319.

[43] P. Courtin, Rev. Chim. Min. 8 (1971) 75.

[44] A. Tahar, S. Benadji, T. Mazari, L. Dermeche, C. Marchal-Roch, C. Rabia, Catal. Lett. 145 (2015) 569.

[45] K. Nomiya, M. Miwa, Y. Sugaya, Polyhedron 3 (1984) 607.

[46] E. Ishikawa, T. Yamase, Bull. Chem. Soc. Jpn. 73 (2000) 641.

[47] R.I. Maksimovskaya, Polyhedron 65 (2013) 54.

[48] A.C. Dengel, W.P. Griffith, B.C. Parkin, J. Chem. Soc.-Dalton Trans. (1993) 2683.

[49] D.C. Duncan, R.C. Chambers, E. Hecht, C.L. Hill, J. Am. Chem. Soc. 117 (1995) 681.

[50] I.D. Ivanchikova, N.V. Maksimchuk, R.I. Maksimovskaya, G.M. Maksimov, O.A. Kholdeeva, ACS Catal. 4 (2014) 2706.

[51] L.I. Kuznetsova, N.I. Kuznetsova, R.I. Maksimovskaya, O.S. Koshcheeva, V.A. Utkin, Kinet. Catal. 54 (2013) 420.

[52] L. Salles, C. Aubry, R. Thouvenot, F. Robert, C. Doremieuxmorin, G. Chottard, H. Ledon, Y. Jeannin, J.M. Bregeault, Inorg. Chem. 33 (1994) 871.

[53] L.I. Kuznetsova, N.I. Kuznetsova, R.I. Maksimovskaya, G.I. Aleshina, O.S. Koscheeva, V.A. Utkin, Catal. Lett. 141 (2011) 1442. 
[54] L.Y. Meng, S.R. Zhai, Z.C. Sun, F. Zhang, Z.Y. Xiao, Q.D. An, Microporous Mesoporous Mat. 204 (2015) 123.

[55] H.F. Wang, R.B. Hu, Y.F. Yang, M.D. Gao, Y.J. Wang, Catal. Commun. 70 (2015) 6.

[56] H. Chen, W.L. Dai, X.L. Yang, R.H. Gao, Y. Cao, H.X. Li, K.N. Fan, Appl. Catal. AGen. 309 (2006) 62.

[57] M.A. Fedotov, R.I. Maksimovskaya, J. Struct. Chem. 47 (2006) 952.

[58] E.P. Talsi, K.V. Shalyaev, K.I. Zamaraev, J. Mol. Catal. 83 (1993) 347.

[59] M.L. Ramos, M.M. Pereira, A.M. Beja, M.R. Silva, J.A. Paixao, V.M.S. Gil, J. Chem. Soc.-Dalton Trans. (2002) 2126.

[60] L.P. Kazansky, B.R. McGarvey, Coord. Chem. Rev. 188 (1999) 157.

[61] G.Q. Zou, W.Z. Zhong, L.Q. Mao, Q. Xu, J.F. Xiao, D.L. Yin, Z.S. Xiao, S.R. Kirk, T. Shu, Green Chem. 17 (2015) 1884.

[62] M. Moudjahed, L. Dermeche, S. Benadji, T. Mazari, C. Rabia, J. Mol. Catal. A-Chem. 414 (2016) 72.

[63] M. Vafaeezadeh, M.M. Hashemi, Catal. Commun. 43 (2014) 169. 